\title{
A Concurrent Multi-Axis Differential Optical Absorption Spectroscopy System for the Measurement of Tropospheric Nitrogen Dioxide
}

\author{
Roland J. Leigh ${ }^{1}$, Gary K. Corlett ${ }^{1}$ Udo Frie $^{1}$, Paul S. Monks ${ }^{2}$ \\ ${ }^{1}$ Earth Observation Science, Space Research Centre, Department of Physics \& \\ Astronomy, University of Leicester, University Road, Leicester, LE1 7RH, United \\ Kingdom \\ ${ }^{2}$ Department of Chemistry, University of Leicester, University Road, Leicester, LE1 \\ 7RH, United Kingdom, author to whom correspondence should be addressed.
}

Submitted to Applied Optics, October 2005 


\begin{abstract}
The development of a new concurrent multi-axis sky viewing spectrometer for monitoring rapidly changing urban concentrations of nitrogen dioxide is detailed. The concurrent multi-axis differential optical absorption spectroscopy (CMAX-DOAS) technique involves simultaneous spectral imaging of the zenith and off-axis measurements of spatially resolved scattered sun-light. Trace gas amounts are retrieved from the measured spectra using the established DOAS technique. The potential of the CMAX DOAS technique to derive information on rapidly changing concentrations and the spatial distribution of nitrogen dioxide in an urban environment is demonstrated. Three example datasets are presented from measurements during 2004 of tropospheric $\mathrm{NO}_{2}$ over Leicester, UK $\left(52.62{ }^{\circ} \mathrm{N}, 1.12^{\circ} \mathrm{W}\right)$. The data demonstrates the current capabilities and future potential of the CMAX-DOAS method in terms of the ability to measure the real-time spatially disaggregated urban $\mathrm{NO}_{2}$.
\end{abstract}




\section{Introduction}

Zenith-viewing UV/Visible scattered light differential optical absorption spectroscopy (DOAS) has been used over a number of decades for the retrieval of atmospheric concentrations of traces species including $\mathrm{O}_{3}, \mathrm{NO}_{2}, \mathrm{BrO}, \mathrm{OClO}, \mathrm{IO}, \mathrm{HCHO}$ and $\mathrm{O}_{4}$. (e.g. ref. $^{1-11}$ ). In recent years, systems incorporating off-axis (non-zenith) measurements have been developed. ${ }^{12-18}$ Off-axis techniques exploit the improved sensitivity of non-zenith measurements to tropospheric trace-gas concentrations owing to the enhanced tropospheric path length of scattered light collected at low elevation angles. Through the incorporation of multiple off-axis viewing geometries, information on the vertical profile and spatial distribution of trace gases can be retrieved.

The application of the DOAS methodology can measure absorption by trace species throughout the path length of scattered solar radiation. ${ }^{19}$ The sensitivity of the measurement to stratospheric and tropospheric absorbers is related to the length of the absorption path through the stratosphere or troposphere. A simplified schematic of the absorption paths is shown in Figure 1. As a general rule the stratospheric path length is modulated by changing solar zenith angle while the tropospheric path length is dominated by changes in instrument viewing geometry. ${ }^{14}$ Tropospheric sensitivity is minimised in the zenith view, as photons are generally scattered in the lower stratosphere and upper troposphere and therefore take a vertical path straight through the boundary layer. Offaxis viewing angles with elevations less than 20 degrees above the horizon have much greater sensitivity to tropospheric concentrations as the last scattering point for the photons received by an instrument is much lower in the atmosphere and is horizontally displaced from the instrument, giving a longer tropospheric absorption path (see for

example ref. ${ }^{17}$ ). The altered viewing geometry results in an increased absorption by tropospheric species in off-axis measurements which can be exploited to retrieve vertical profile and spatial information on absorbing species.

[Figure 1 here] 
Much work has concentrated on the measurement of background concentrations of $\mathrm{NO}_{2}$ and halogen species in remote rural or polar regions. ${ }^{8,18}$ For such measurements the temporal resolution of the instrument is not a primary concern as concentrations are expected to change over timescales of hours or days rather than minutes. As such, consecutive measurements from different viewing geometries are appropriate with a total scan of all viewing axes taking several minutes. However, for analysis of rapidly varying and spatially inhomogeneous concentrations of trace species in the boundary layer, simultaneous measurement of all viewing angles is highly desirable. A concurrent multiaxis DOAS (CMAX-DOAS) system has been developed in this work to measure five or more viewing geometries simultaneously and has been tested in urban conditions to measure the concentration of boundary-layer nitrogen dioxide $\left(\mathrm{NO}_{2}\right)$.

Elevated concentrations of $\mathrm{NO}_{2}$ have been linked with various adverse health effects and are thus subject to a number of EU directives and targets. ${ }^{20}$ Analysis of the localised and varying sources including vehicular traffic and industry requires relatively high time resolution in order to provide meaningful and useful data in such inhomogeneous air masses. Data are presented to show the potential of concurrent multiaxis DOAS to retrieve rapidly varying boundary layer concentrations of $\mathrm{NO}_{2}$. At present monitoring of $\mathrm{NO}_{2}$ emissions and concentrations is problematic, with point measurements including in-situ chemiluminescence detectors providing much of the available urban data. ${ }^{20}$ The CMAX-DOAS technique demonstrates the potential to provide a significant new tool for remote sensing of inhomogeneous plumes in the urban environment with elevated $\mathrm{NO}_{\mathrm{x}}$ concentrations. This paper details the experimental setup of a CMAX-DOAS instrument and the determination of the performance characteristics.

\section{Experimental}

The CMAX-DOAS instrument consists of three main elements, the input optics, the imaging spectrometer, and a CCD-based detection system. Figure 2 shows a schematic representation of the instrument. Each element will be detailed individually. 
[Figure 2 here]

\section{Input optics}

The input optics for the CMAX-DOAS system comprise of five telescopes which collect scattered solar radiation from independent viewing angles. The individual telescopes consist of black-anodized aluminium alloy tubes of $5 \mathrm{~cm}$ diameter with an $\mathrm{f} / 2$ plano-convex lens fixed at one end and an SMA fiber-optic connector at the focal point of the lens at the opposite end. The telescopes are securely mounted onto an aluminium frame encased within a weather-proof box. The entrance windows of this box are made from anti-reflection coated glass (Edmund Optics BK7) and are placed $7.5 \mathrm{~cm}$ from the plano-convex lenses of the telescopes. The windows are slanted to be parallel to the telescopes and a black-anodized aluminium alloy tube between the window and the telescope ensures that only light coming through the corresponding window will arrive at the respective telescope. Every piece of aluminium alloy in the head assembly is black anodized to minimize stray light effects. The nature of the plano-convex lens assembly combined with the anti-reflective entrance windows produces a constrained field of view. This is desirable to maximize the differentiation between the air masses sampled by the photons collected in each telescope.

For operation in cold conditions heating pads are installed in the head assembly. These strips in conjunction with platinum resistance thermistors avoid problems of changes in optical properties with temperature, or ice and snow accumulation on the entrance windows and optics. A container of desiccant (silica gel) is incorporated into the design. The head unit is mounted on a $4 \mathrm{~m}$ extendable pole on the roof of the Space Research Centre at the University of Leicester $\left(52.62{ }^{\circ} \mathrm{N}, 1.12^{\circ} \mathrm{W}\right)$ which ensures unobstructed viewing geometries on all axes. The viewing geometries used in this experiment are $2^{\circ}, 5^{\circ}, 10^{\circ}, 15^{\circ}$ and $90^{\circ}$ (zenith) elevation above the horizon with all nonzenith telescopes pointing directly north. 
The optical connection from the telescopes to the spectrometer comprises five fibre-optic cables of $200 \mu \mathrm{m}$ diameter. Each of these fibres connects a single telescope to the input of an Oriel multi-track fibre ${ }^{21}$ which aligns all fibres into a vertical array suitable for input into an imaging spectrometer.

The telescopes and fused silica fiber-optics used in this experiment have an exit cone f-number of 2. The MS257 spectrometer system used in this experiment requires an entrance cone f-number of 3.9. In order to maintain sufficient vertical separation in the imaging spectrometer and to avoid stray light it is necessary to adapt the exit cone of the fibre to the required entrance cone of the spectrometer. This is achieved by the use of an f-number matcher ${ }^{21}$ which alters the focal length of the input cone and refocuses the image onto the entrance aperture of the spectrometer.

\section{The Spectrometer and CCD detector}

[Table 1 here]

The instrumental details are summarised in Table 1. The Oriel MS257 imaging spectrometer is a Czerny-Turner design with corrected toroidal optics for multi-track spectroscopy. The spectrometer system provides the wavelength dispersion in the $\mathrm{x}$-axis while maintaining the necessary separation of input signals in the $y$-axis. The corrected toroidal optics reduce astigmatism in the focal plane increasing comparability of resulting signals from different locations on the CCD chip. The grating used for these experiments is an aluminium ruled grating with 600 groves $\mathrm{mm}^{-1}$ and a blaze wavelength of $400 \mathrm{~nm}$.

The detector is a Marconi 48-20 back-illuminated, frame-transfer, UV-coated CCD. The CCD chip has 1033 rows and 1072 columns of pixels each of which is $13 \mu \mathrm{m}$ wide by $13 \mu \mathrm{m}$ high giving a total imaging area of approximately $13.4 \mathrm{~mm}$ x $13.9 \mathrm{~mm}$. The detector is housed inside a vacuum unit, with a two-stage Peltier cooler with additional water-cooling. The CCD is kept at a constant $-21.0{ }^{\circ} \mathrm{C}+/-0.1{ }^{\circ} \mathrm{C}$ to minimise dark current signal and detector noise. The frame-transfer ability permits the CCD images to be captured without the use of a shutter mechanism. 
The f-number matcher, spectrometer and CCD camera assembly are housed inside an insulated, sealed box in an air-conditioned lab which stabilises the temperature inside the box to $19{ }^{\circ} \mathrm{C}+/-0.2{ }^{\circ} \mathrm{C}$.

[Figure 3 here]

A typical CCD image is shown in Figure 3, with 550 of the available 1033 rows of the $\mathrm{CCD}$ being stored. Corrections are incorporated into extraction software to compensate for any tilt in the spectral images on the CCD. The 48-20 chip does not have a dump gate so charge builds up between reads, this is manifested in an over-exposed region at the top of each frame. The over-exposed region is monitored to ensure that it does not bleed charge into the zenith fibre reading and then discarded. Each imaged fibre covers approximately 30 rows and fibres are spaced about 100 rows apart. Spectra extracted are an average of the 30 rows over which each fibre image spanned, with dark current and stray light correction applied by subtraction of values taken from 50 rows either side of each fibre. Analysis of dark current and stray light correction values (see later) indicates little spectral information and minimal temporal variation, confirming adequate thermal stability for the CCD and sufficient vertical separation of the spectral images.

The entrance slit in the MS257 spectrometer was removed, i.e. the ending of the fibre bundle was serving as entrance slit, in order to achieve a broader instrument line shape with minimal variability across the focal plane. Variations in line shape across the focal plane of the imaging spectrometer are of considerable importance as spectra from each viewing angle are compared with spectra from the zenith telescope, which is imaged on a different section of the focal plane. If significant differences exist between instrument line shapes from the different axes, uncertainties are introduced into the DOAS retrieval. With the entrance slit removed, the end of the multi-track fibre is the effective entrance aperture of the instrument, focused at the focal point of the spectrometer by the f-number matcher. 


\section{Image analysis and spectral fitting}

The DOAS technique ${ }^{19}$ is based on the application of the Beer-Lambert Law which describes the absorption of radiation at a given wavelength $\lambda$ by $i$ gaseous species of concentration $\rho_{i}$ and absorption cross section of $\sigma_{i}(\lambda)$.

$$
I(\lambda)=I_{0}(\lambda) \cdot \exp \left(-\sum_{i} \int_{0}^{L} \sigma_{i}(\lambda) \rho_{i} d s\right)
$$

A measure of the total absorbance along a path length $\mathrm{L}$ from $i$ absorbers is therefore given by:

$$
\ln \left(\frac{I_{0}(\lambda)}{I(\lambda)}\right)=\sum_{i} \int_{0}^{L} \sigma_{i}(\lambda) \rho_{i} d s
$$

In atmospheric DOAS, the term $I_{0}$ is the intensity of the reference spectrum taken at solar noon, which takes the shortest path through the atmosphere. The term $I$ is the intensity of a spectrum taken at any other time (object spectrum), which takes a longer path through the atmosphere and is therefore subject to increased absorption throughout the extra path length. However, absorption by trace species is not the only influence on solar intensity in the atmosphere. Scattering and absorption processes from air molecules, cloud droplets and aerosols also attenuate incoming radiation. The effects of most scattering can be removed through the fitting of an appropriate polynomial which removes the broad-band structure in the resulting differential spectrum $\ln \left(\frac{I_{0}(\lambda)}{I(\lambda)}\right)$. Narrow-band features are also introduced owing to changes in the shape of Fraunhofer structures between $I_{0}$ and $I$ as a result of rotational Raman scattering. ${ }^{22}$ Such features can be removed through the inclusion of a synthetic Ring spectrum in the fitting process. ${ }^{11}$ By simultaneously fitting all absorption cross sections of known absorbers, plus the polynomial parameters and Ring spectrum it is possible to derive a differential slant column density for a given absorber, being the integrated concentration over the 
additional photon path length through the atmosphere in the object spectrum relative to the reference spectrum.

Spectra are analysed in this work with the WinDOAS software package. ${ }^{23}$ Instrument calibration is performed using WinDOAS, including the instrument line shape measurement and an accurate wavelength calibration. The measured instrument line shape is used to create the simulated Ring spectrum. All fitted cross sections are also convolved with the measured wavelength-dependent instrument line shape using the WinDOAS software.

Additionally, dark current corrections were performed with an independent wavelength calibration for each fibre through a least squares fitting routine using the Kurucz solar spectrum ${ }^{24}$ to compensate for wavelength shifts between spectra from different viewing geometries.

The absorption cross sections used in the DOAS analysis are shown in Table 2. A third order polynomial is also included in the fitting process, together with the Ring spectrum and a constant offset parameter which compensates for any stray light in the system.

[Table 2 here]

A typical result of the spectral analysis is shown in Figure 4. All fitted cross sections are plotted with the "residual", which is the signal which has not been apportioned to any known absorber and is a measure of instrument noise and an accumulation of system errors. Also included in the fit, but not plotted in Figure 4 are the third-order polynomial, the Ring spectrum, and the constant offset parameter.

[Figure 4 here] 
The residual structure in Figure 4 has an RMS value of 0.00205 and exhibits some non-random structure. However, the important $\mathrm{O}_{4}$ and $\mathrm{NO}_{2}$ fits are considerably stronger and as can be seen in the data in panels $4 a$ and $4 c$, are affected only minimally by such an RMS residual.

\section{Instrumental Characteristics}

The established method of sequential multi-axis DOAS ${ }^{18,25}$ benefits from the utilisation of a single optical system for the measurement of all spectra. This implementation results in the effects of instrumental artefacts such as instrument line shape variability and spatial variations in detector sensitivity being obviated by the mechanics of the DOAS technique ${ }^{19}$ because these cancel out in equation (2) if $I$ and $I_{0}$ are measured by the same instrument. The challenge of concurrent MAX-DOAS is to minimise or compensate for such effects as spectra from slightly different optical systems are used in the same analysis. Although the spectrometer and CCD are single units, different pixels on the CCD are used for each viewing angle, and therefore considered as different optical systems.

Stray light and dark current corrections need to be applied to sequential MAXDOAS as they have potential temporal variability. The primary additional variables necessary to include in concurrent MAX-DOAS are the variability of sensitivity of the optical systems to each specific wavelength for each fibre input and the variability of the instrumental response across the focal plane. The variability of the instrument sensitivity is a function of grating efficiency, mirror efficiency, obstructions (dirt, dust etc) in the optical path, and above all, the sensitivity of individual CCD pixels. The summation of all these effects we have termed specific instrument sensitivity as it is manifested in the response of a given pixel measuring a given wavelength to a specific intensity of input. The specific instrument sensitivity changes the shape of the measured spectrum, which has considerable consequences for a DOAS fit. It is necessary to be able to know to a reasonable level of accuracy, what any given spectrum would have looked like had it 
been measured using the same optical system as the zenith spectrum. To this end, measurements are made of specific instrument sensitivity with respect to the zenith pixels.

Specific instrument sensitivities are measured by illuminating each input fibre with light from a stabilised Quartz-Tungsten-Halogen lamp. Spectra are recorded on each fibre using precisely the same retrieval mechanism applied during normal measurement operation. A correction factor $(R)$ is then calculated for each pixel as follows:

$$
R_{(\alpha, n)}=\frac{I_{(z e n, n)}^{c}}{I_{(\alpha, n)}^{c}}
$$

where, $I_{(z e n, n)}^{c}$ is the intensity of the zenith spectrum at pixel $n$ and $I_{(\alpha, n)}^{c}$ is the intensity of the off-axis spectrum at the same pixel.

An example set of spectra and resultant correction factors are shown in Figures 5 and 6. Small features are clear in fibres 1 and 3 around pixel 840, and a strong broad feature is evident in the fibre 3 reading around pixel 500. These features are almost certainly due to artefacts on the surface of the CCD.

[Figure 5 here]

[Figure 6 here]

The correction factors (as per equation (3)) are applied to the relevant pixels in each set of off-axis spectra to produce spectra which are directly comparable to those recorded by the zenith optical system. These correction factors are measured regularly and are stable under normal static operation but highly variable if the system alignment is altered.

Corrections for the variability in instrument line shape across the focal plane are more complex. At this stage of development, the approach was taken to minimise such 
variability and quantify the resulting errors, with correction procedures a focus of future work.

\section{Instrument Noise and errors}

The residual signal remaining at the end of a DOAS fit is made up of two components, namely the instrument noise and the systematic errors. The instrument noise results from two sources, photo electron noise from the detector, and electronic noise from the various components between the CCD pixels. ${ }^{26}$ The systematic errors result from inaccuracies in the many components used in the DOAS analysis, including the cross sections, the Ring effect, the instrument line shape and the wavelength calibration.

The photo electron noise is caused by the statistical distribution of the number of photo electrons detected by the CCD device. This is proportional to the square root of the number of observed photo electrons. As the integration time of the CMAX-DOAS system was automatically monitored to maximise the CCD usage, the number of observed photo electrons was maximised for each reading and remained reasonably constant throughout a measurement period.

The electronic noise is caused by characteristics of the electronic components used to collect the signal from the CCD pixel. Such detector noise is proportional to the number of CCD images averaged for each spectrum.

Despite the elimination of as many systematic errors as possible, instrumental constraints still produce certain inaccuracies. Each potential source of systematic error was independently investigated to estimate the contribution to the total fitting error.

Stray light between fibres is a potential source of systematic error. This could occur in the spectrometer optical system if light from higher diffraction orders or from sources other than the fibres reach the detector. The degree of stray light signal between fibres was investigated by monitoring signal strength between the imaged fibres. Any variability over the day in the signal strength between the fibres would indicate that the 
signal contained either stray light not entering the system via the fibre-optic system, or photons scattered from one of the fibres. The signal strength as measured on the $9^{\text {th }}$ November 2004 at points on each fibre, and points between all fibres are shown in Figure 7.

[Figure 7 here]

In Figure 7 the data from the clear morning and evening demonstrate the relative intensities of the different viewing geometries in non-cloudy conditions. The arrival of cloud at $7 \mathrm{am}$ coincides with the initiation of the automatic integration-time software, which keeps the maximum value on the CCD to between 50 and $70 \%$ of full-well capacity. The signal strength between fibres is plotted in Figure 7 although they lie so closely together that their individual signals are indistinguishable. These low measurements indicate negligible stray light signal, with negligible errors caused by either stray light entering the system, or through signals being diffracted by the spectrometer optics, and superimposed on another signal. The negligible signal monitored above the zenith fibre also confirms the lack of influence of the charge build-up between frames.

The variability of the stray light signal between the fibres gives a measure of electronic noise. The RMS from the daily mean value is 2.5 counts. Using the approximation of an average signal strength on the fibres of 1500 counts, this produces an uncertainty of approximately $0.2 \%$. The signal strength on the 2 degree view is significantly lower, with an average signal between $90^{\circ} \mathrm{SZA}$ at dawn, and $90^{\circ} \mathrm{SZA}$ at dusk of only 46 counts above the measured dark current. This leads to errors from electronic noise of approximately $5.3 \%$ on this fibre under these conditions. It should be noted that cloud structures very strongly influence the relative intensities of each viewing direction, and these errors are therefore subject to significant daily variability. The low intensity on the 2 degree view on this day can be considered as a worst case scenario.

\section{Instrument Line Shape}


Systematic errors are also introduced through assumptions made in the convolution of cross sections and other fitted parameters with a given instrument line shape. The first of these assumptions is that the instrument line shape is Gaussian. With the spectrometer entrance slit removed, this assumption is reasonably accurate. However, certain asymmetries still exist. The instrument line shape was measured with a mercury line lamp and a Gaussian was fitted to this measured instrument line shape to estimate the errors introduced through the use of a Gaussian line shape to convolve cross sections. The results of this fitting process are shown in Figure 8. The errors caused by this asymmetry are determined by the strength of Fraunhofer structure in relation to the differential signal from the absorber. These errors are best estimated operationally and can be found in the results section.

[Figure 8 here]

The dependence of the instrument line shape on the horizontal and vertical position in the focal plane was investigated using recorded atmospheric spectra. As part of a rigorous wavelength calibration procedure including shift and squeeze procedures the WinDOAS software fits standard instrument line shape parameters (eg. full-width half-maximum (FWHM)) to sub-windows of recorded spectra. This procedure permits accurate wavelength calibration, and investigation of the variability of the line shape both within an individual spectrum, and between spectra imaged in different areas of the focal plane. Figure 9 shows the measured instrument line shape from all five viewing geometries.

[Figure 9 here]

The errors owing to the variability of the instrument line shape are introduced when spectra from one fibre are used as reference spectra for another fibre. The errors introduced in such a procedure vary according to the FWHM of the two spectra at a given wavelength. One technique to calculate these errors is to calculate the error from two normalised Gaussian curves of the appropriate FWHM's. From the data in Figure 8, 
errors varied across the fitting window and between fibres, and with a maximum around $470 \mathrm{~nm}$ with values of approximately $3.5 \%$ for analysis of 15-degree spectra (FWHM of $1.14 \mathrm{~nm}$ ) with a zenith reference (FWHM of $1.38 \mathrm{~nm}$ ).

The wavelength calibration of the spectra was performed by the WinDOAS software, and this calibration was used to shift reference spectra where necessary to be on the same grid as the off-axis spectra. Wavelength calibrations were taken to be accurate to within half a pixel, or $0.04 \mathrm{~nm}$. Possible errors introduced through inaccurate wavelength calibration were calculated to be $0.8 \%$, using a FWHM of $1.4 \mathrm{~nm}$. A summary of contributory errors in the DOAS fit can be found in table 3 .

[Table 3 here]

The total theoretical fitting error of $1.5 \%$ for individual fibre measurements applies for analysis of spectra from a single viewing geometry. Errors introduced by the variability of the instrument line shape affect analysis of off-axis spectra with a zenith reference only, and increase the theoretical error to approximately 5\%.

Additional errors on slant column density measurements will be introduced by errors in measured cross sections. Subsequent calculations of absolute concentrations and profile shapes will be subject to errors in calculations of photon paths through the atmosphere.

Statements on errors for DOAS analysis are problematic, owing to the variability of the influence of a given variability in signal with the strength of the differential absorption features between the reference spectrum, and the spectrum under analysis. For spectra with very weak differential structure, even the slightest instrumental inaccuracy can introduce very significant errors, which are difficult to quantify in a theoretical calculation. 
The high RMS residual on the 2 degree elevation is caused by the variability in the instrument line shape, and the very low intensity of the 2-degree elevation image which is an inherent disadvantage of this instrumental system. The integration time of the CCD is determined by the brightest viewing geometry, which changes with cloud conditions and solar zenith angle. The telescope pointing at 2 degrees elevation consistently receives the lowest light intensity, and therefore the signal has a larger relative contribution from $\mathrm{CCD}$ dark current and electronic noise. For this reason data from the 2 degree elevation view is only used with a 2 degree reference spectrum.

\section{Results and Discussion}

The instrument was installed on the roof of the Space Research Centre at the University of Leicester at the end of $2003\left(52.62^{\circ} \mathrm{N}, 1.12^{\circ} \mathrm{W}\right)$. Three example sets of data from 2004 will be presented to show the capabilities of the CMAX-DOAS instrument. The first set results from a self-consistency test run with two zenith telescopes. An example of a full day's data from all axes is then presented to demonstrate the information contained in the slant column densities derived from the chosen fitting window. The third set is a rare set of cloud-free data from the morning of $17^{\text {th }}$ Jan 2004 which demonstrates the potential for analysis of locally emitted $\mathrm{NO}_{2}$.

\section{Self-consistency tests}

In order to assess the true capabilities of the instrument, a self-consistency test was performed with two independent zenith telescopes. The lowest elevation angle telescope was replaced with a telescope pointing to the zenith. The secondary telescope was mounted outside the main head unit and had the same dimensions as the original (primary) zenith telescope and was fitted with an $8 \mathrm{~cm}$ cylindrical baffle to avoid direct sunlight entering the telescope.

Spectra from both telescopes were imaged 300 rows apart on the CCD to simulate an average image separation and variability of instrument function. The spectra were 
extracted from the CCD and analysed using the method and parameters described in the experimental section (see also Table 2). The correlation between measurements from both telescopes was tested to establish the ability of the CMAX-DOAS instrument to produce consistent concurrent slant column densities from two independent inputs. In addition to comparing slant column densities from the two telescopes, the influences of using a reference spectrum from other areas of the CCD was investigated through analysis of both sets of spectra with exchanged reference spectra. These reference spectra were shifted to the correct wavelength grid, but no other corrections were applied. Four sets of data were therefore generated all measuring the same air mass at the same time. These datasets are denoted as follows:

Prim/Prim - for the original (primary) zenith view using its own reference.

$\mathrm{Sec} / \mathrm{Sec}$ - for the secondary zenith view, using its own reference.

$\mathrm{Prim} / \mathrm{Sec}$ - for the primary zenith spectra, using a reference spectrum from the secondary zenith view.

Sec/Prim - for the Secondary zenith spectra, using a reference spectrum from the primary zenith view.

The results from this form of analysis are shown in Figure 10.

[Figure 10 here]

The measurements show generally good agreement from the almost indistinguishable lines in the top panel of Figure 10, where the diurnal variation of the $\mathrm{NO}_{2} \mathrm{SCDs}$ from the four aforementioned datasets are shown. The slant column densities range from $1 \times 10^{16}$ to $2.5 \times 10^{17} \mathrm{~mol} / \mathrm{cm}^{2}$ which is typical for conditions encountered in Leicester. At such levels, the uncertainties in individual measurements are a low proportion of the total signal. The extent of the differences between measured slant column densities can be seen in the correlation plot in the lower panel of Figure 10. The comparability of the two datasets can be initially seen in the best fit line between Prim/Prim and Sec/Sec, with an offset of $4 \times 10^{14} \mathrm{~mol} / \mathrm{cm}^{2}$, and an $\mathrm{R}^{2}$ value of 0.9979 . The 
gradient of this line is below 1, at 0.9764, with measurements from the new zenith measuring on average $2.4 \%$ lower than the original zenith. These marginally lower measurements may have been the result of the limit of the viewing accuracy of the telescopes, resulting in a slightly different viewing geometry. The correlation between Prim/Prim and Prim/Sec is the initial test of the errors introduced through the use of an alternative reference spectrum from another section of the CCD. The agreement within less than $0.7 \%$, with an offset of $7 \times 10^{14} \mathrm{~mol} / \mathrm{cm}^{2}$ and an $\mathrm{R}^{2}$ value of 0.9999 indicate that the difference in instrument function between these two fibres has introduced only very minimal errors to the DOAS system.

An example fit from the Prim/Prim, and Prim/Sec analyses is shown in Figure 11 to demonstrate the additional residual structure introduced through such an analysis, and the robust nature of the DOAS fitting technique to derive accurate concentrations for a strong absorber such as $\mathrm{NO}_{2}$.

[Figure 11 here]

As the variability of instrument line shape between measured spectra is of such importance to this instrumental design, an additional form of error analysis was performed on the data of $9^{\text {th }}$ November 2004. Spectra from the primary zenith view were analysed using a convolved version of the original reference spectrum. The reference spectrum was deconvolved using a $1.1 \mathrm{~nm}$ Gaussian instrument line shape (the measured instrument line shape geometry on this day), and reconvolved with line shapes of 1.101 $\mathrm{nm}, 1.2 \mathrm{~nm}, 1.3 \mathrm{~nm}$ and $1.4 \mathrm{~nm}$ Gaussians. The initial 1.101 dataset tests the accuracy of the analysis technique including the deconvolution and reconvolution routines, and calculates the uncertainty due to the asymmetry of the instrument line shape. The 1.2 to $1.4 \mathrm{~nm}$ datasets cover the range of instrument line shapes present in the CMAX-DOAS configuration. Results from this analysis are shown in Figure 12.

[Figure 12 here] 
The dataset using a $1.101 \mathrm{~nm}$ Gaussian instrument line shape confirms the suitability of the analysis, with negligible errors introduced in the additional processing steps. The slope of 0.9975 , with an offset of $-2 \times 10^{14} \mathrm{~mol} \mathrm{~cm}^{-2}$ also indicates minimal errors resulting from asymmetry of the instrument line shape of the measured spectra. Such errors for this instrument can be estimated at below $0.5 \%$. The datasets for 1.2 to $1.4 \mathrm{~nm}$ instrument line shapes display little additional random errors, but do have significant offsets and biases, evident from the best-fit equations in the correlation plot in the lower panel of Figure 12. Such systematic errors are likely to be due to the convolution of fitted cross sections with the instrument line shape of the reference spectrum, which is the form of analysis performed under normal operating conditions. Even at extreme cases of a $1.1 \mathrm{~nm}$ spectrum being analysed using a $1.4 \mathrm{~nm}$ reference spectrum, the error introduced is less than $10 \%$ and under normal circumstances is nearer to $5 \%$.

\section{Example measurements}

A typical day of data from the summer of 2004 can be seen in Figure 13 with retrieved data for $\mathrm{NO}_{2}, \mathrm{O}_{4}, \mathrm{O}_{3}$ and $\mathrm{H}_{2} \mathrm{O}$. In the analysis the spectrum from the zenith view measured at noon was used as reference for the off-axis views, providing maximum spatial information.

[Figure 13 here]

The stratospheric dominance of the ozone signal can be seen in the lack of dependence of measurement on viewing geometry, with the slant column density purely dependent upon solar zenith angle. The $\mathrm{NO}_{2}$ slant column density shows both tropospheric and stratospheric signals while the $\mathrm{O}_{4}$ and $\mathrm{H}_{2} \mathrm{O}$ signals as expected are dominated by a tropospheric signal. The oxygen dimer $\mathrm{O}_{4}$ has a known vertical profile and absorption features throughout the UV and visible ${ }^{27}$ and can therefore be used as an indicator photon path length and subsequently scattering properties in the atmosphere. Clouds, haze and aerosols influence photon path lengths by altering atmospheric scattering properties. While thick clouds can increase path lengths through increased 
scattering between and within clouds, thin cloud, haze or high aerosol concentrations will reduce path lengths in off-axis measurements, as scattering of photons is more likely to occur near the CMAX-DOAS instrument. ${ }^{28}$ Therefore, on this day, the $\mathrm{O}_{4}$ slant column densities indicate light non-uniform cloud as shown by the non-smooth curves, and the proximity of measurements from different axes when compared with Figure 14. More cloud and aerosol effects are evident in the morning than the evening where dusk measurements almost resemble clear-sky conditions.

The $\mathrm{NO}_{2}$ slant column density contains information on stratospheric $\mathrm{NO}_{2}$, contained in the solar zenith angle dependence of measurements at dawn and dusk, particularly in the zenith measurement which is least influenced by tropospheric concentrations. The diurnal increase in stratospheric $\mathrm{NO}_{2}$ (caused by the photolysis of $\mathrm{N}_{2} \mathrm{O}_{5}$ ) can be seen in the increased SZA dependence in the dusk measurements over dawn. In addition, tropospheric concentrations are clearly evident in the separation of the off-axis signals, and short temporal features. The most significant features that do not coincide with cloud events are at about 12 noon and $6.30 \mathrm{pm}$. Path length changes indicated in $\mathrm{O}_{4}$ measurements will also influence $\mathrm{NO}_{2}$ measurements. For example, cloudy features appearing in the $\mathrm{O}_{4}$ column densities at 10 am and $3 \mathrm{pm}$ also appear as enhancements in the $\mathrm{NO}_{2}$ slant column densities.

Clear sky conditions are preferable for investigating instrumental sensitivity to tropospheric $\mathrm{NO}_{2}$, as path length enhancements owing to clouds can be discounted. A set of clear-sky data from $17^{\text {th }}$ January 2004 will be used to demonstrate the potential of the CMAX-DOAS instrument to measure the rapidly varying concentration and spatial distribution of $\mathrm{NO}_{2}$ in the urban environment. On this day there was a significant cloudfree period and favourable wind conditions to sample city-centre emissions.

Slant column densities of $\mathrm{NO}_{2}$ and $\mathrm{O}_{4}$ from the 17th January are shown in Figure 14. A zenith reference spectrum from 11.30am was used in the analysis of all spectra, being the last clear-sky zenith spectrum taken on this day. Confirmation of the cloud-free conditions during the morning can be seen in the smooth $\mathrm{O}_{4}$ slant column densities from 
all axes until $11.30 \mathrm{am}$. The detection of changing concentrations of $\mathrm{NO}_{2}$ is confirmed by the rapidly varying $\mathrm{NO}_{2}$ slant column densities despite the smooth path length changes indicated by the $\mathrm{O}_{4}$ slant column densities.

[Figure 14 here]

Two major episodes of increased tropospheric $\mathrm{NO}_{2}$ can be seen on this morning, peaking soon after 9am and just before 12am. The analysis of the finer structure of these peaks provides information on the transport of these two plumes, their spatial extent, and their concentration of $\mathrm{NO}_{2}$. Figure 15 shows $\mathrm{NO}_{2}$ column densities on an expanded time scale from 9:20 to 9:50 am. For this analysis the reference spectrum from each axis was used, rather than a single zenith reference. Although this loses some profile information on $\mathrm{NO}_{2}$ concentrations, it retains the structure of individual peaks and maximises the accuracy of each slant column density measurement.

[Figure 15 here]

The wind speed on the $17^{\text {th }}$ Jan 2004 was approximately $1.6 \mathrm{~ms}^{-1}$ coming from a northerly direction (data from Leicester City Council). As the instrument is placed to the south of the city centre, this would result in plumes from the city centre being transported slowly through each viewing direction of the CMAX-DOAS instrument. The progression through the viewing geometries can be clearly seen. Owing to the nature of the recording cycle in the CCD to PC interface, a measurement is missed every 6 to 10 minutes. In this time period, measurements are missing at 9:22, 9:29, 9:33 and 9:42. The missing measurements at 9:29 and 9:42 are particularly unfortunate in this particular case as they coincide with the two peaks, and cautious interpolation is required.

Information on these plumes can be gained from the amplitude of these peaks, their width, and the temporal shift between each viewing direction. These values can be found in Table 5. Further work will fully explore the wealth of information contained within such temporally resolved measurements of slant column densities of $\mathrm{NO}_{2}$. 
[Table 4 here]

Successful tests have already been completed with a total of 7 axes, with a theoretical maximum of 20 axes possible for this spectrometer and CCD configuration. Additional axes provide further information on plume dimensions and dynamical transport, which could be considerably augmented by the location of two such instruments with intersecting fields of view.

\section{Conclusions}

A new concurrent multi-axis DOAS system using an imaging spectrometer to simultaneously image distinct multiple spectra onto a single CCD has been demonstrated. Through characterisation of the instrument response function for each pixel, it has been shown to be possible to perform reliable DOAS fits using reference spectra from the zenith view which is imaged on a different section of the CCD to the off-axis spectra. Two independent measures of accuracy were performed. A calculation of fitting error due to an accumulation of measurable instrumental artefacts and uncertainties produces figures of $1.5 \%$ error for analysis on a single fibre, and approximately $5 \%$ error on analysis involving spectra from different sections of the focal plane. Correlation analysis of concurrent measurements from similar viewing geometries indicates consistent results from different axes to within $2.4 \%$. The use of reference spectra from another axis or with an altered instrument line shape introduces errors in slant column densities. However, these errors are quantified to be less than $10 \%$ under the entire range of instrument line shapes measured by this instrument, and were measured at less than $0.7 \%$ using spectra taken on $9^{\text {th }}$ November 2004. These two sets of analysis provide estimates of the random and systematic errors in the DOAS fitting procedure for a concurrent multi-axis DOAS instrument.

The high temporal resolution of this instrument permits identification of individual plumes as they pass through each viewing geometry. Temporal resolution of a 
few seconds is possible with this instrument although the signal to noise ratio decreases to the square of the integration time.

With fitting errors safely below $10 \%$, the CMAX-DOAS instrument provides a significant new tool in urban $\mathrm{NO}_{2}$ monitoring. The ability to track plume progression through the viewing geometries has yet to be fully exploited, with considerably increased information available through the use of multiple instruments, and increased numbers of axes.

\section{Acknowledgements}

The authors wish to thank Michel van Roozendael and Caroline Fayt at the Belgian Institute for Aeronomy for their invaluable advice and assistance with the WinDOAS software. We also acknowledge the NDSC and the participants in the 2003 Andøya intercomparison campaign whose generous support assisted considerably during the development of this instrument. Parts of this work were funded under NERC contract NER/S/A/06294. 
Figure1

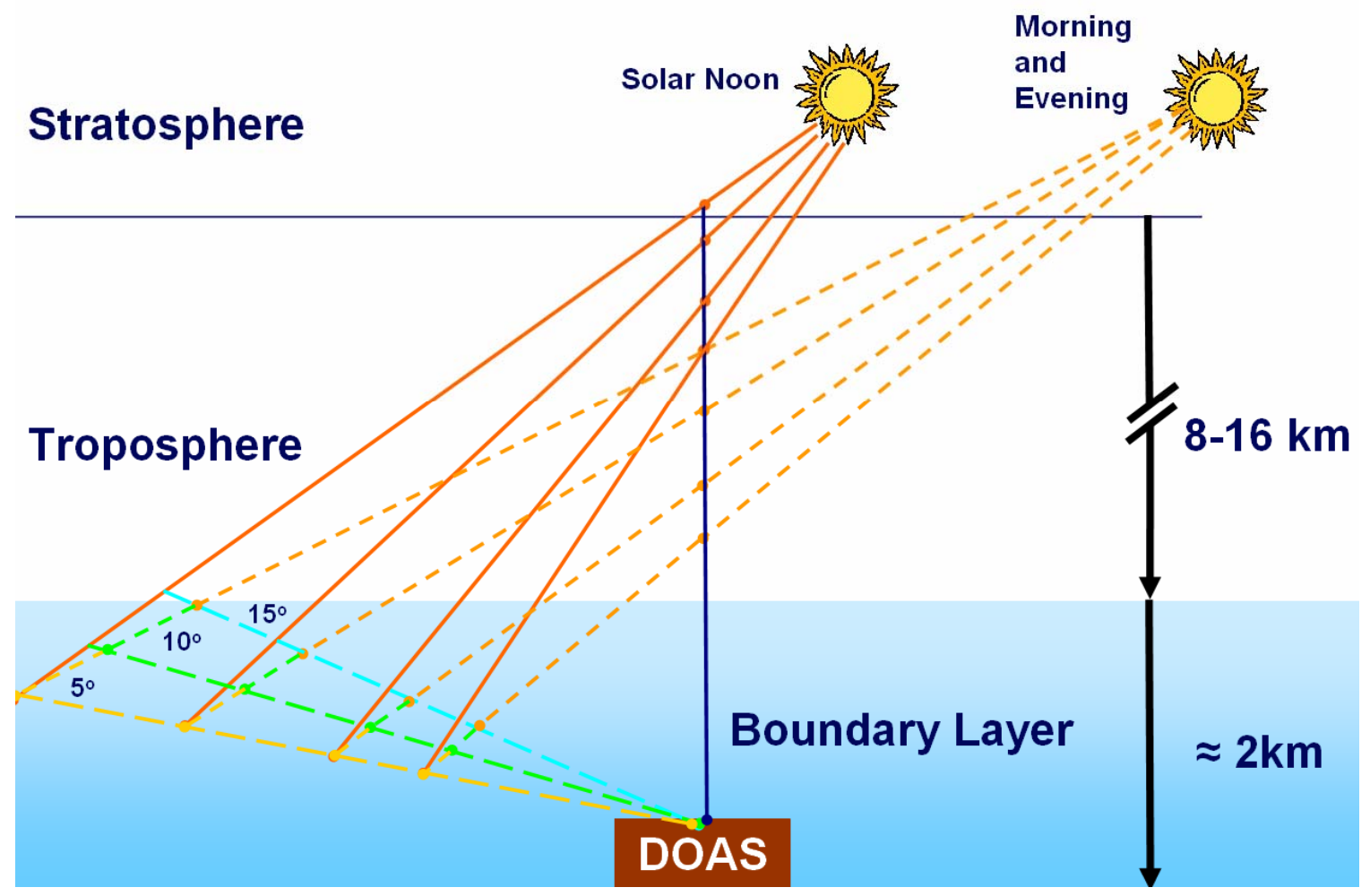


Figure 2

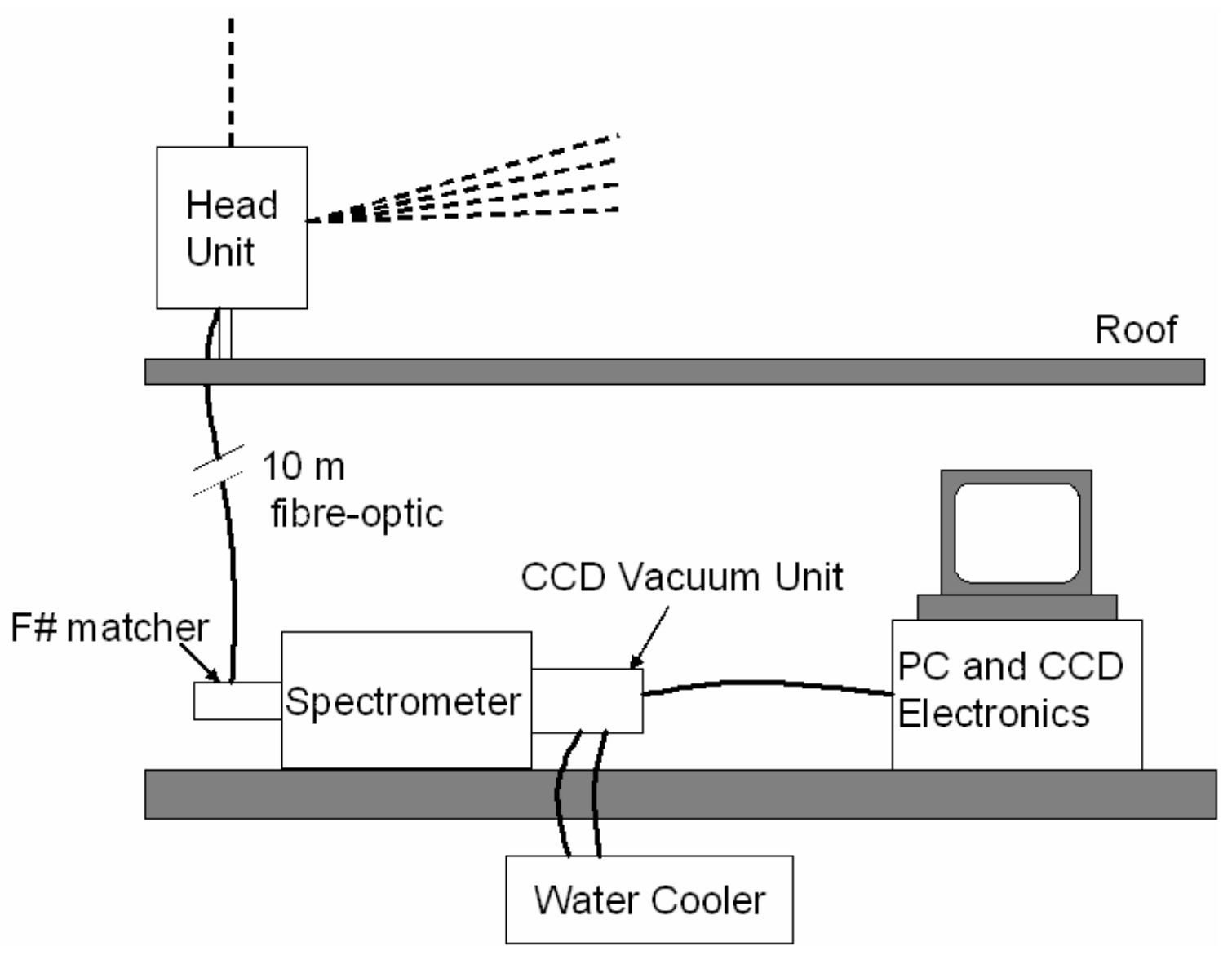


Figure 3

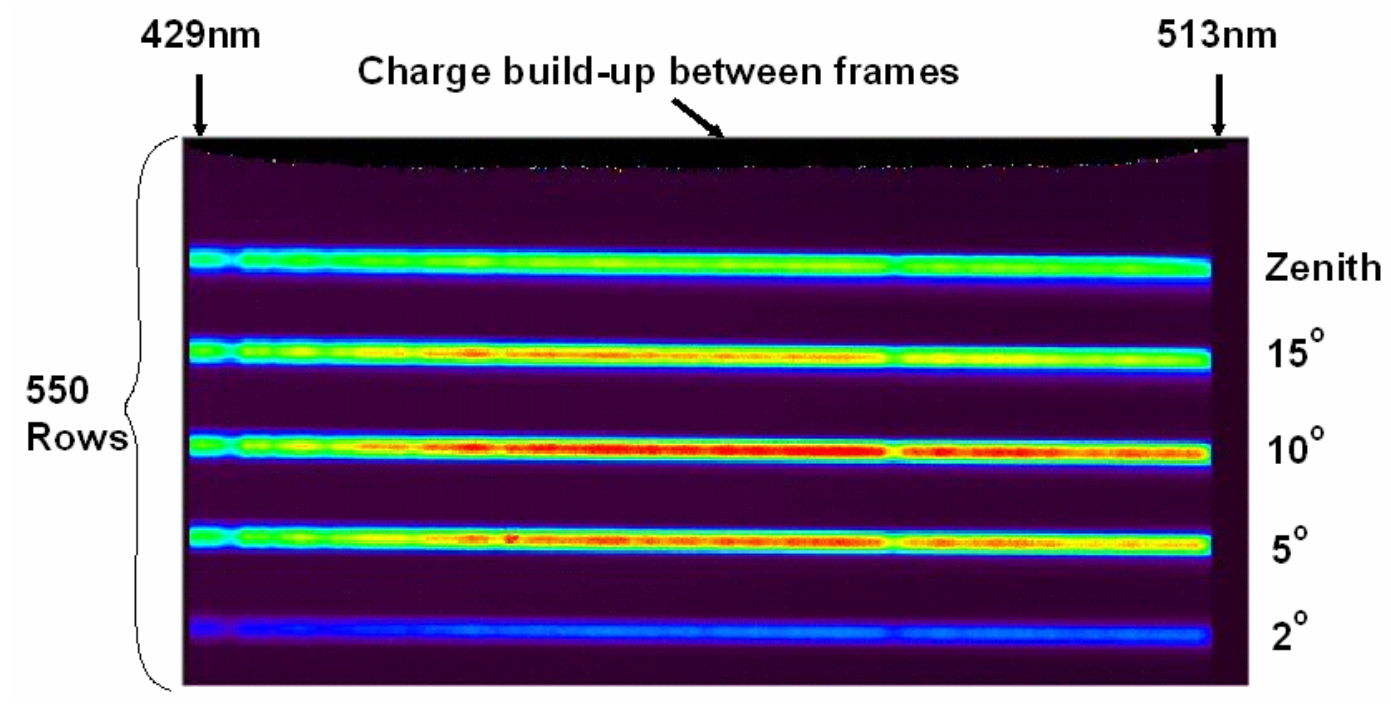




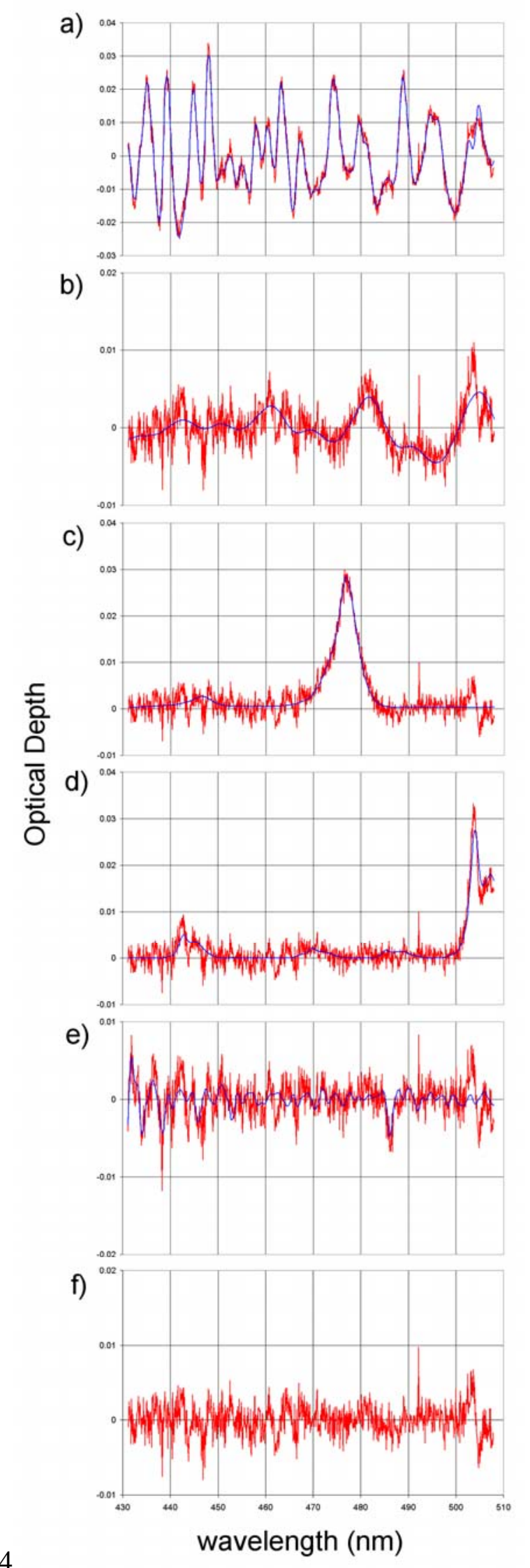

Figure 4 
Figure 5

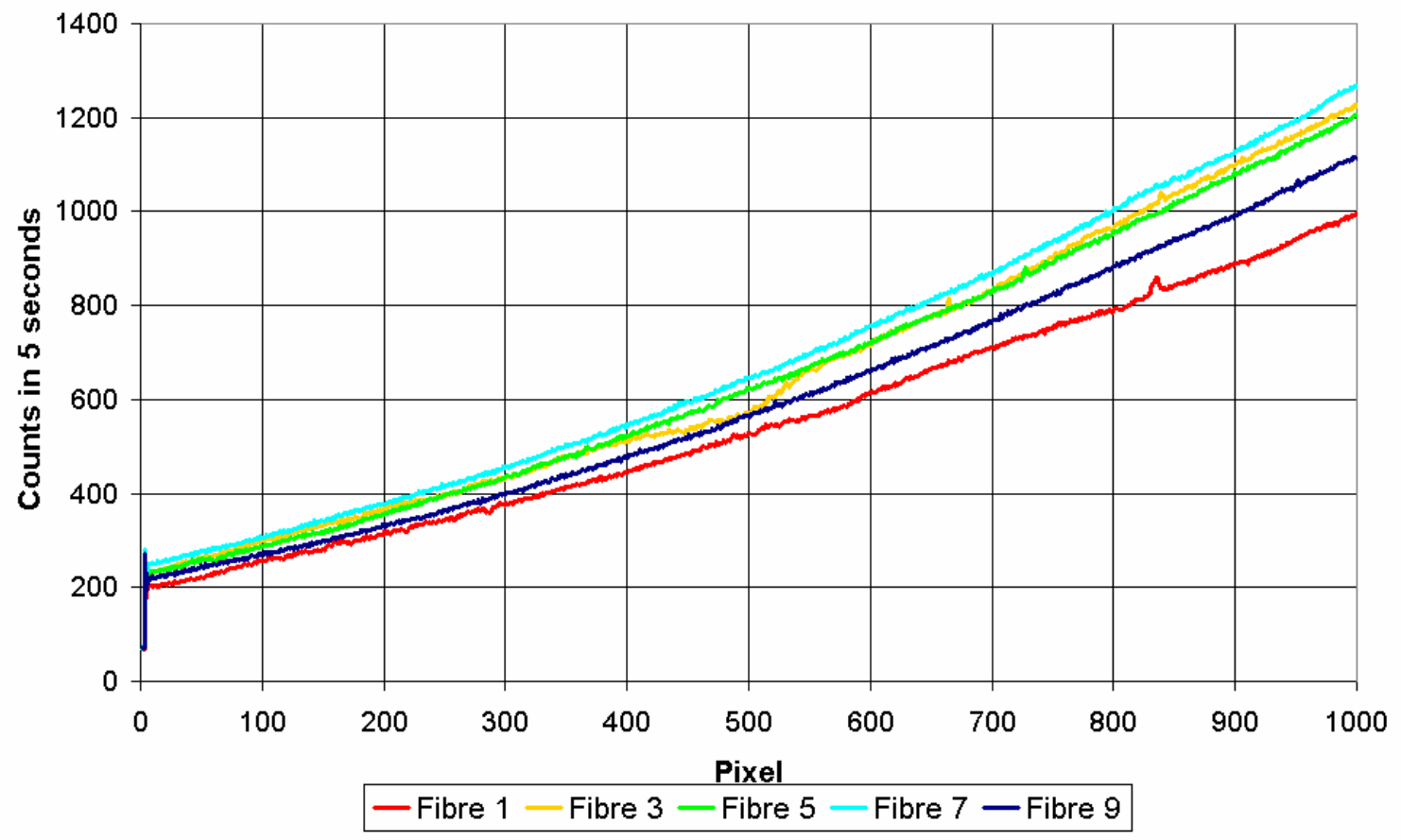


Figure 6

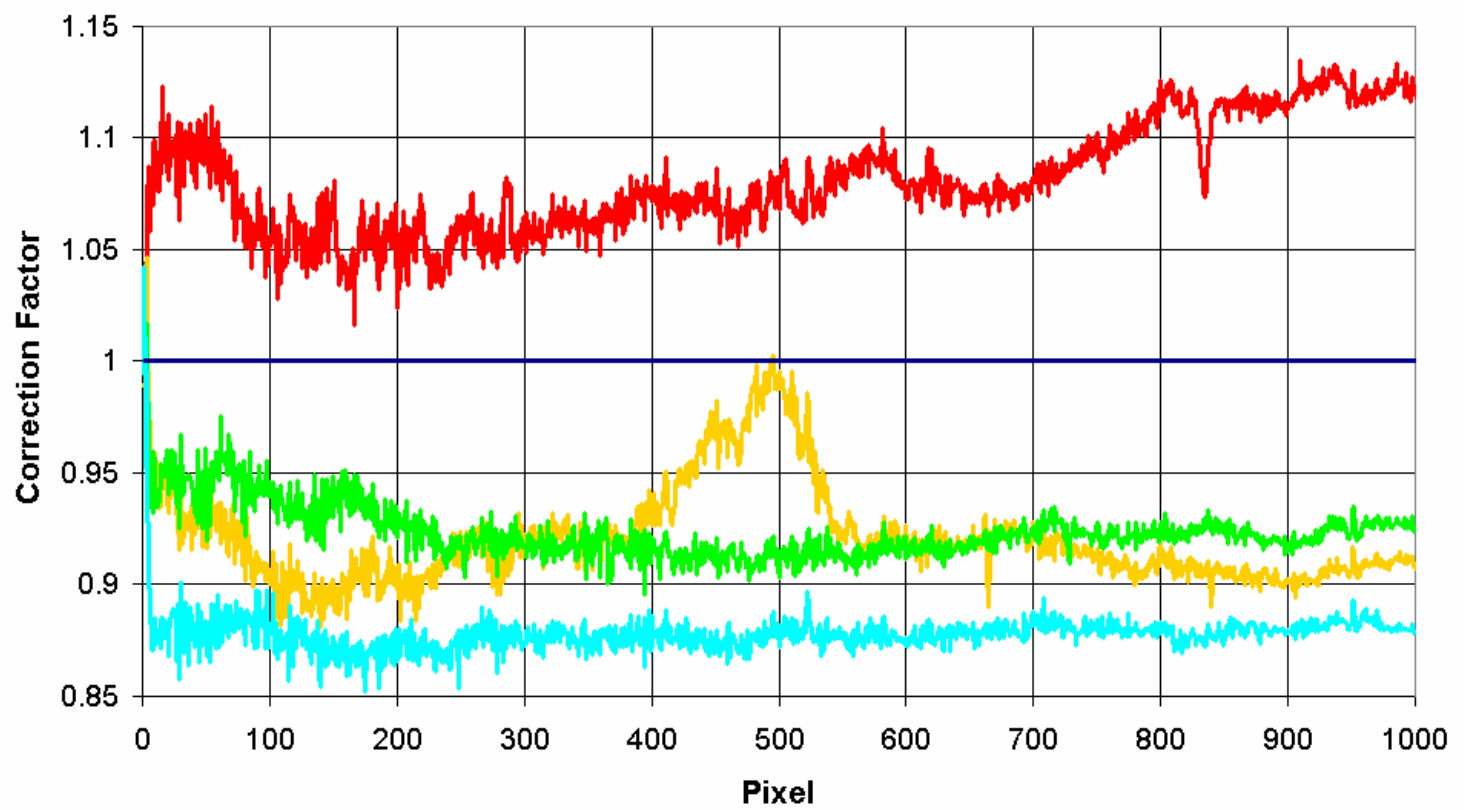

-Fibre 1 -Fibre 3 -Fibre 5 -Fibre 7 -Fibre 9 
Figure 7

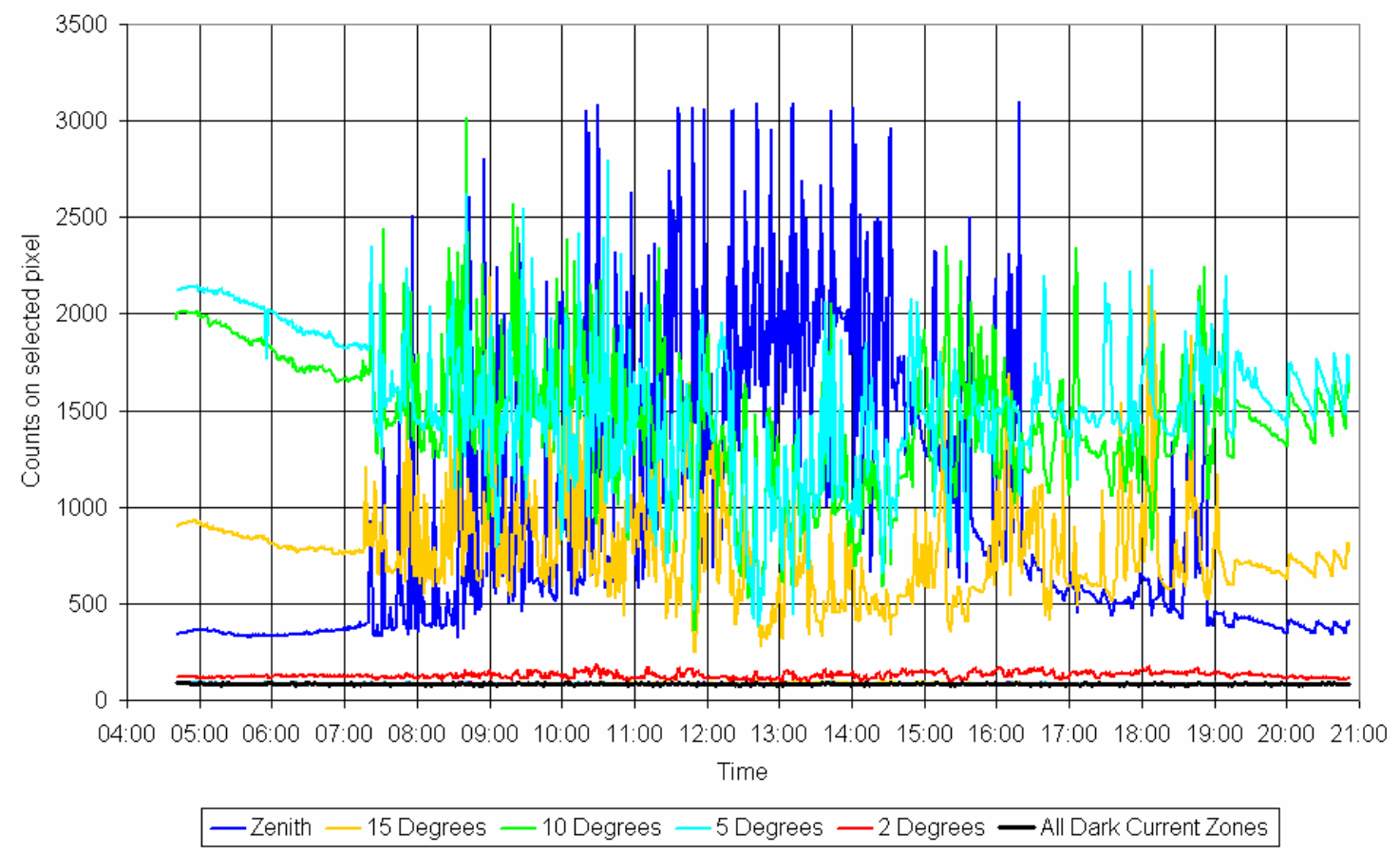


Figure 8

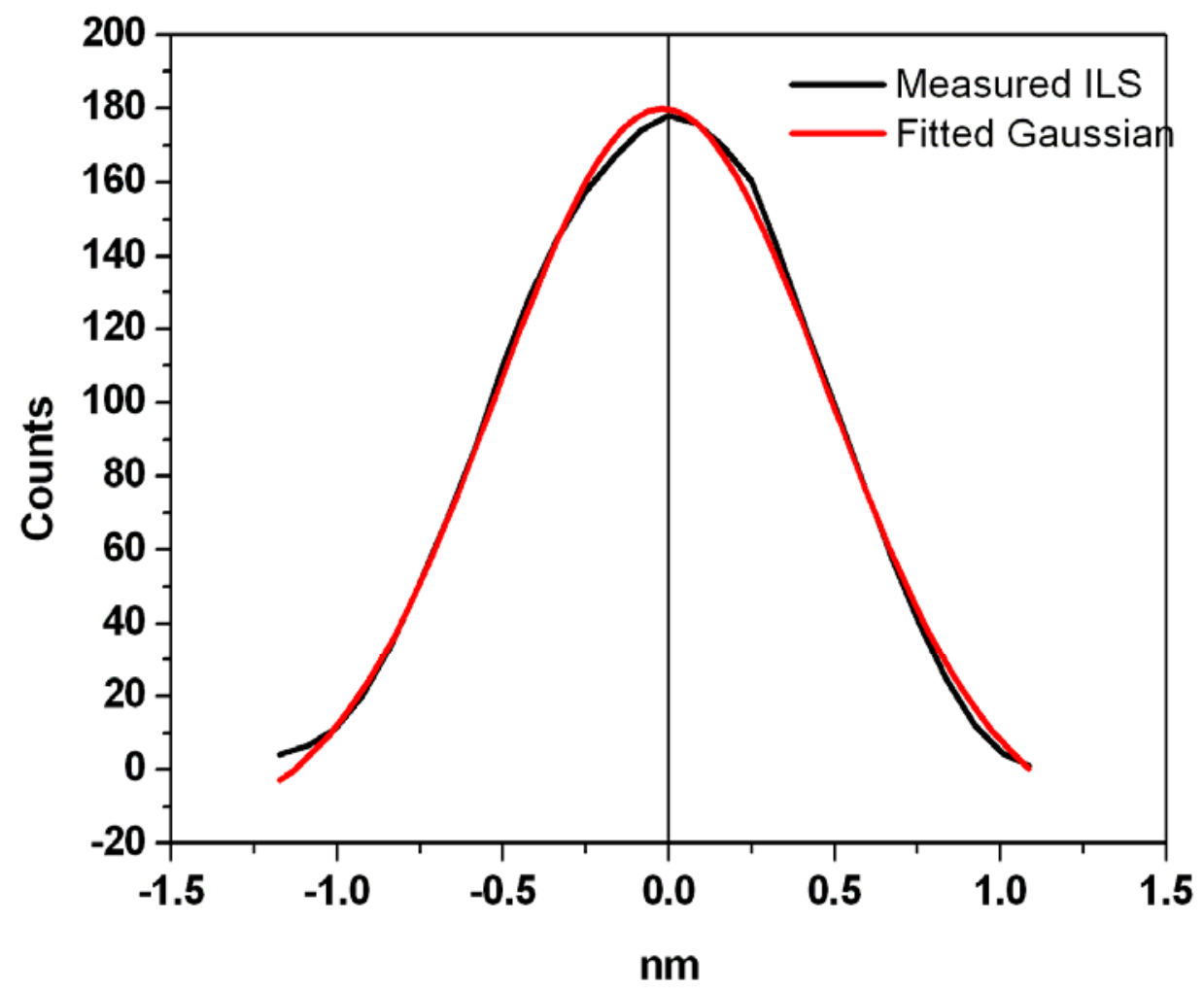


Figure 9

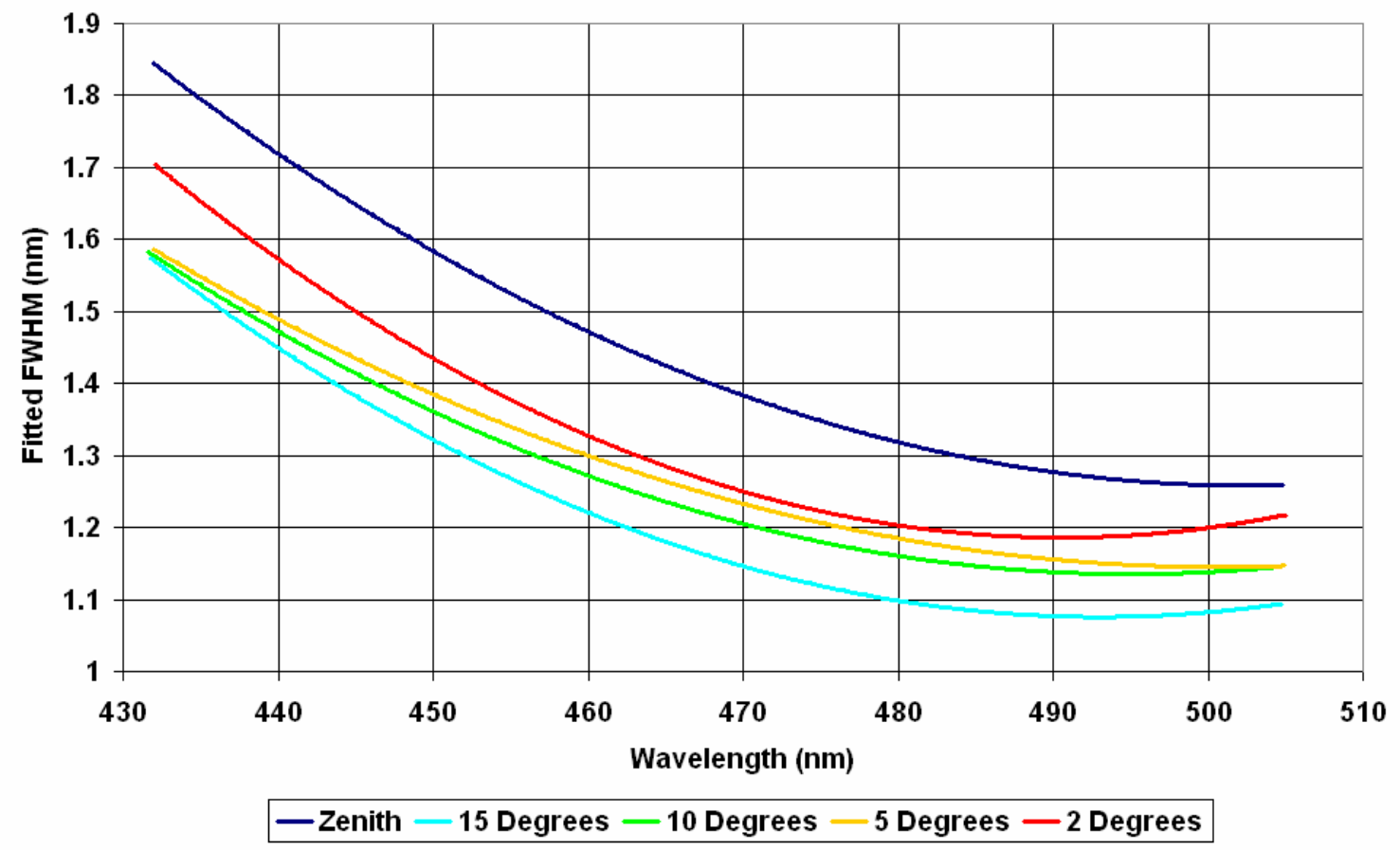


Figure 10

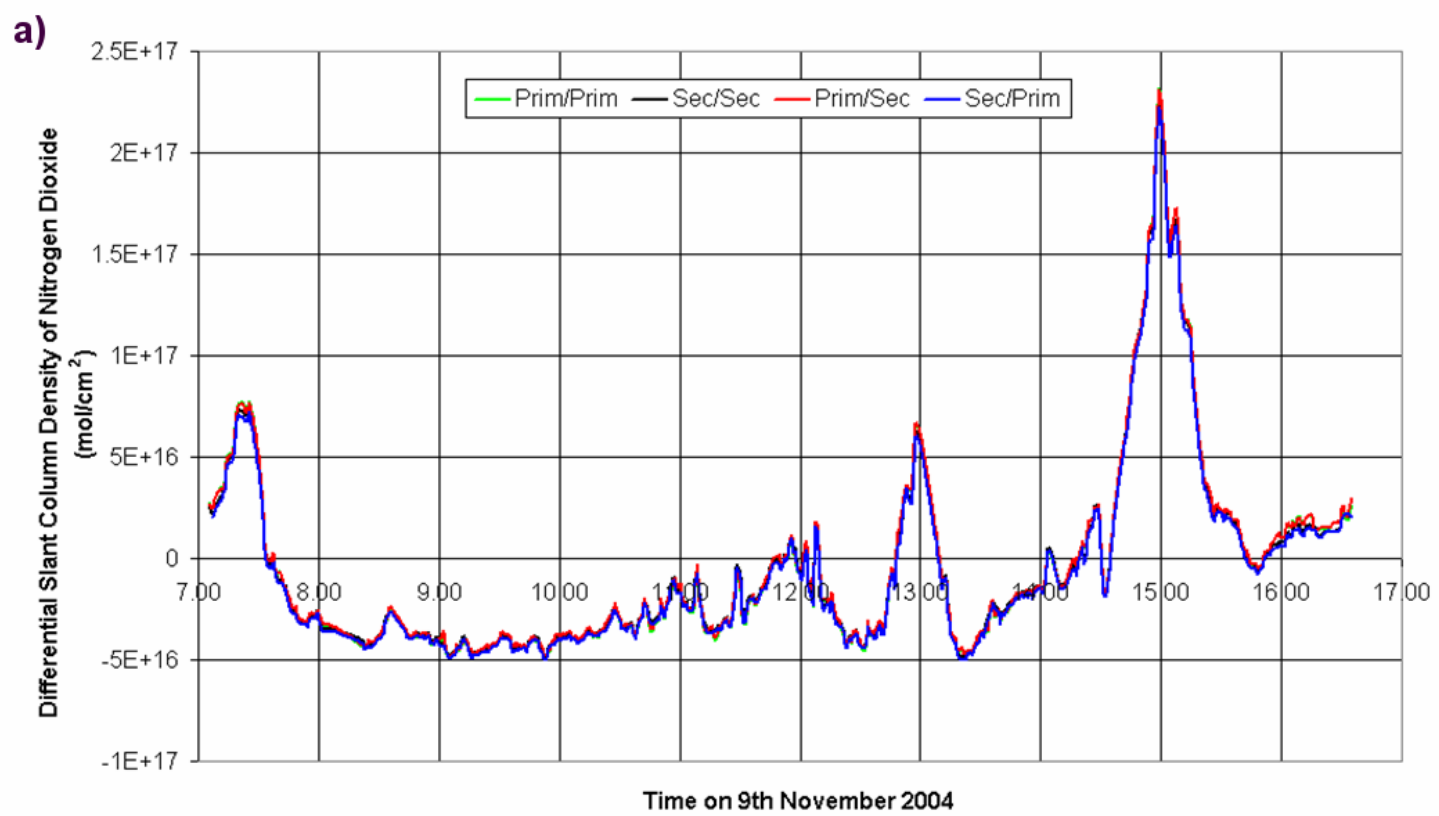

b)

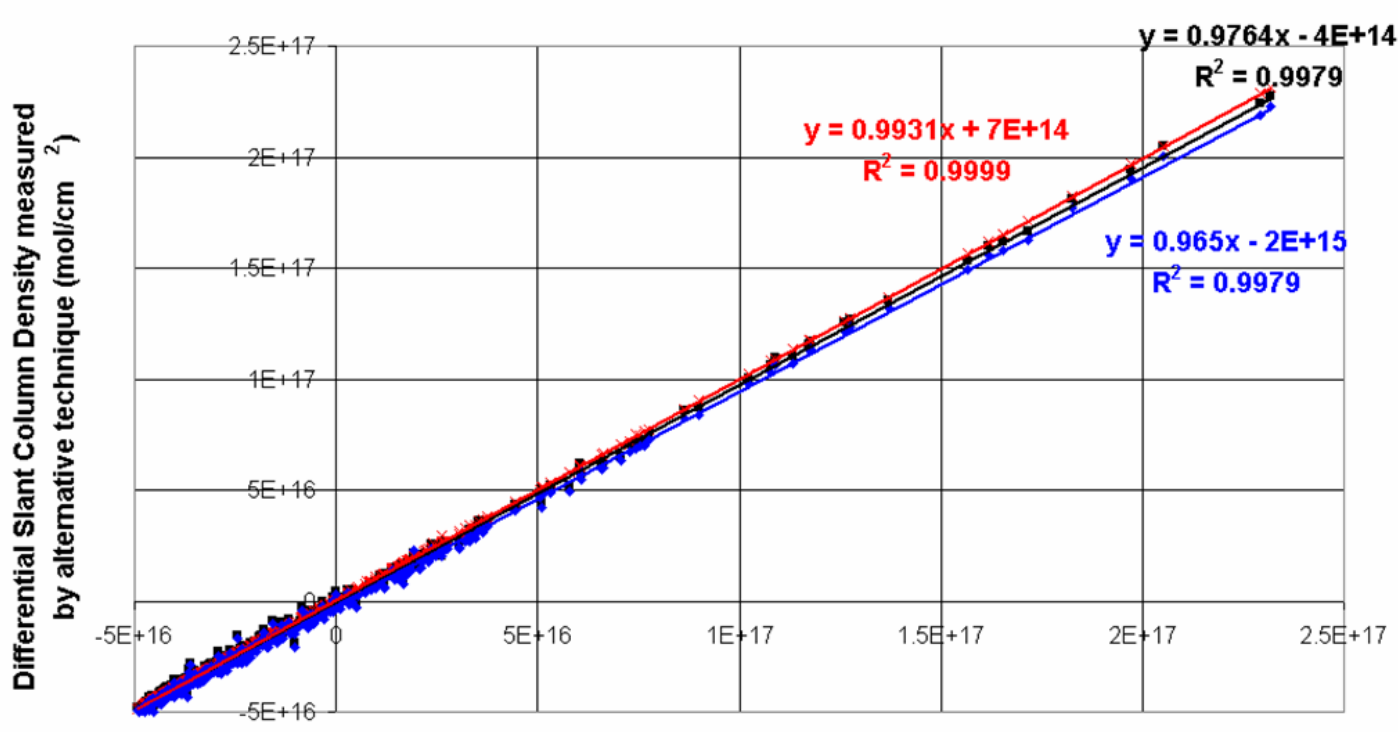

Differential Slant Column Density measured by original Zenith telescope with own reference spectrum $\left(\mathrm{mol} / \mathrm{cm}^{2}\right)$

- Sec/Sec $\times$ Prim/Sec - Sec/Prim —Best fit (Sec/Sec) —Best fit (Prim/Sec) —Best fit (Sec/Prim) 

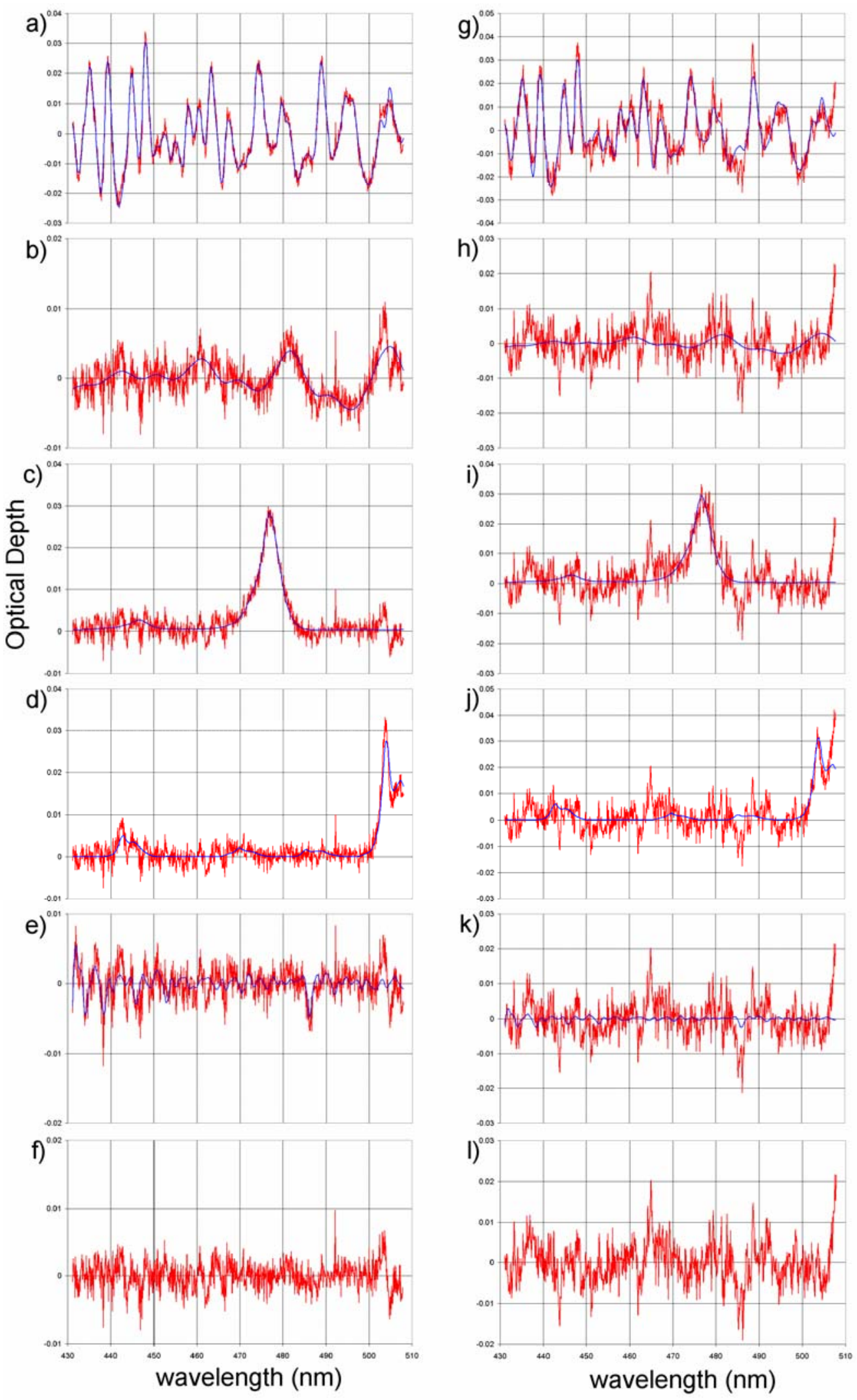

h)
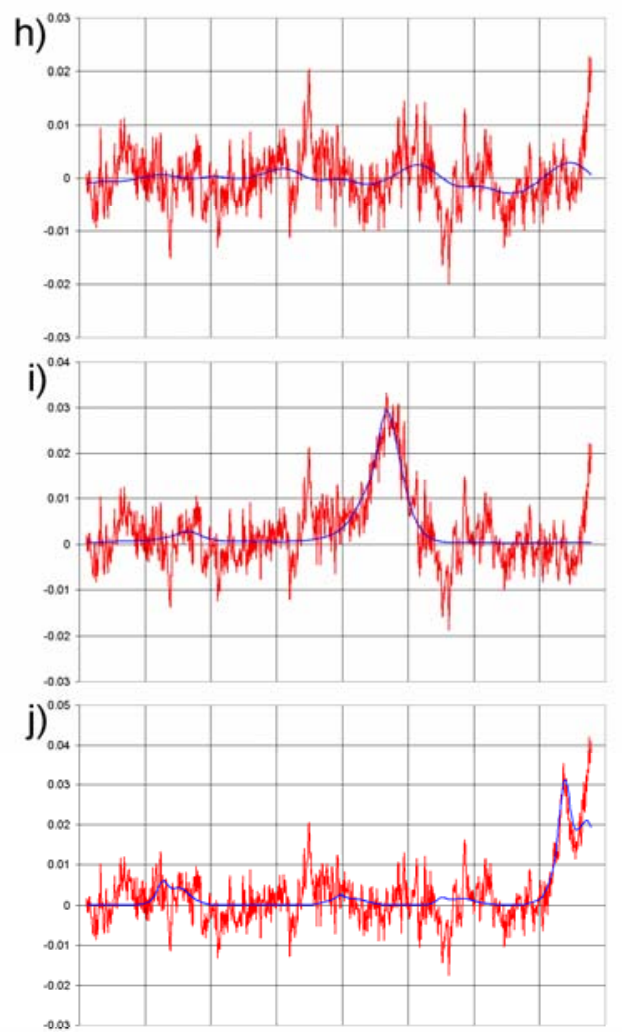

k)
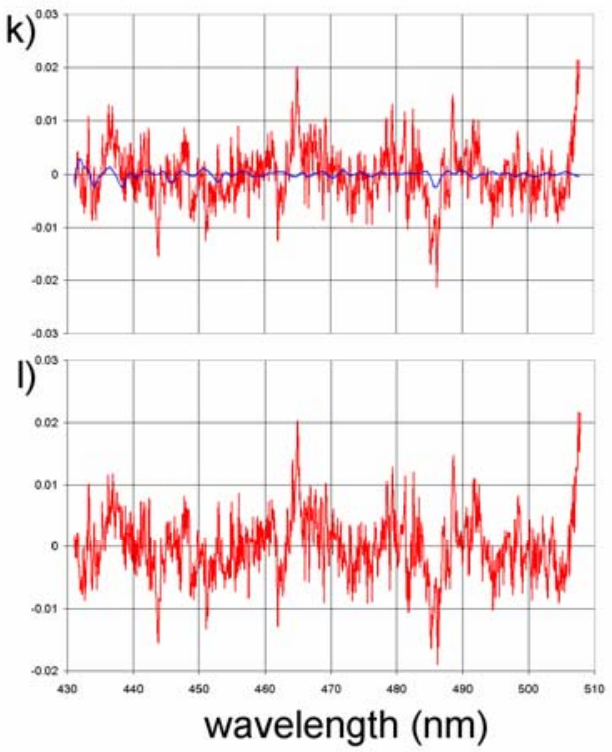

Figure 11 
Figure 12
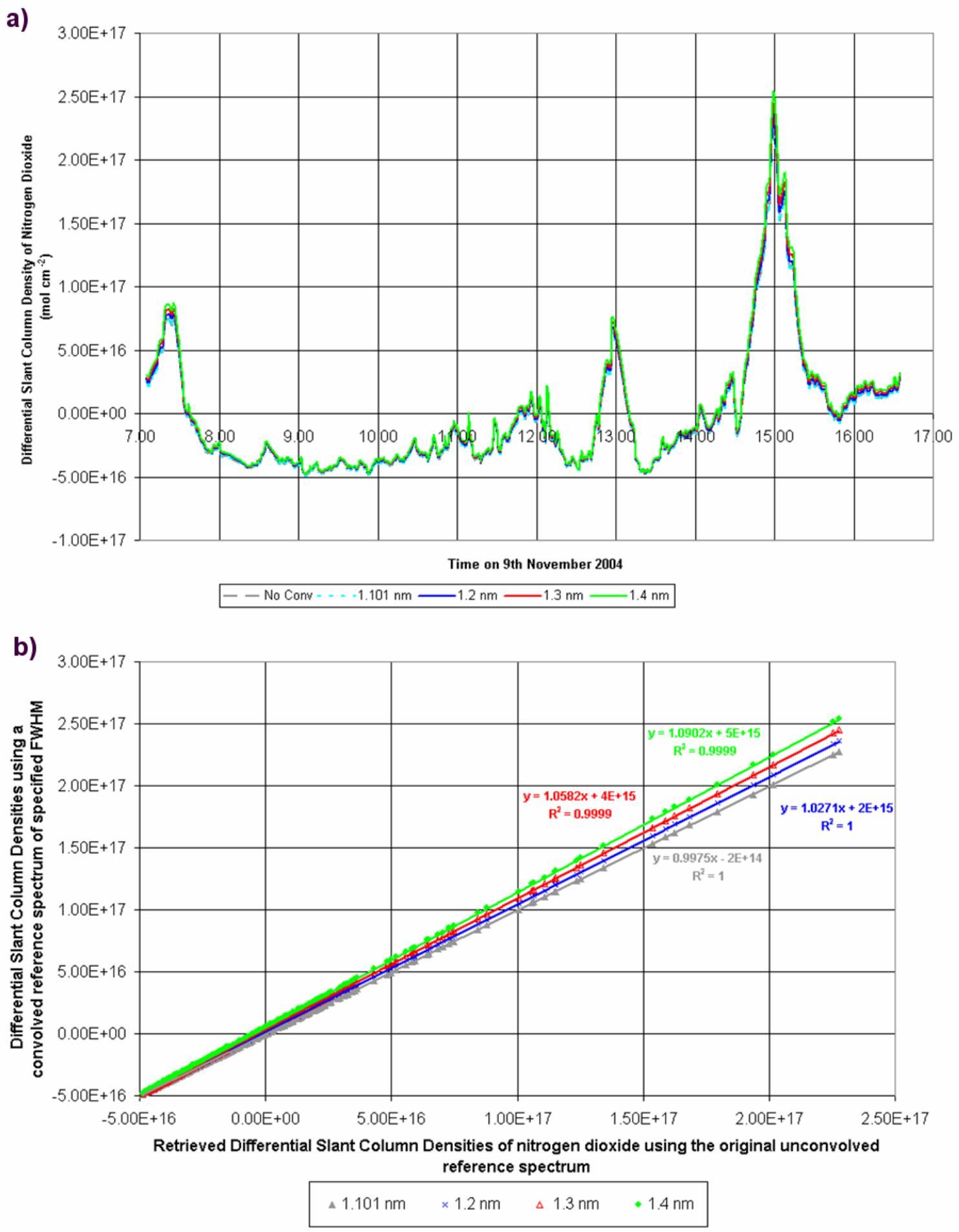
Figure 13

a)

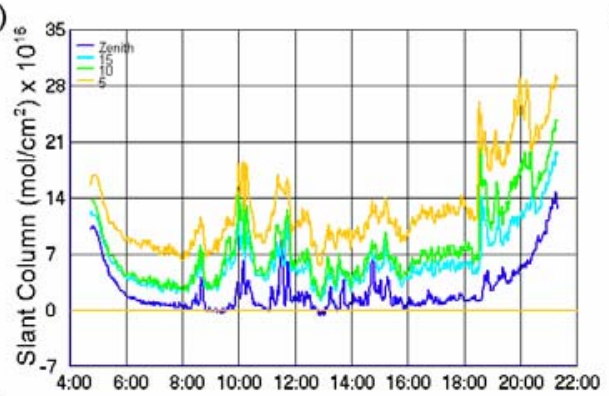

c)

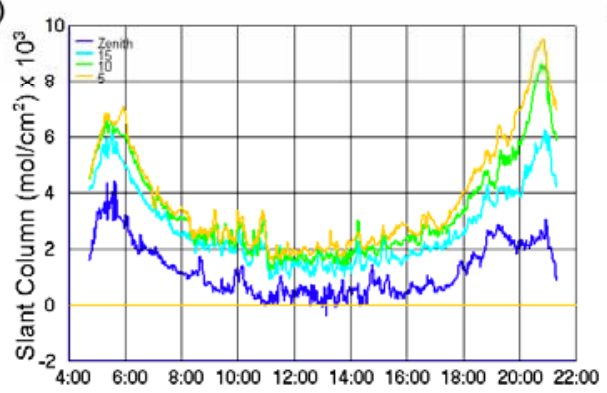

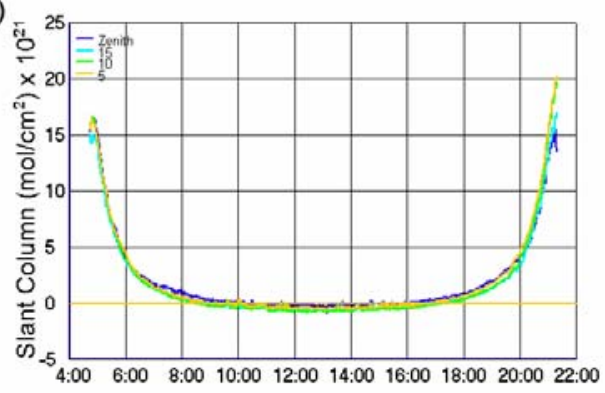

d)

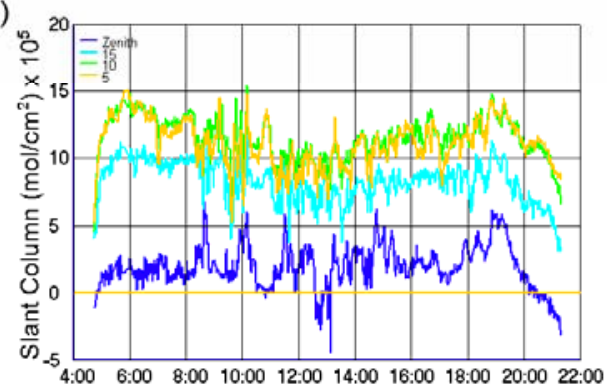


Figure 14

a)

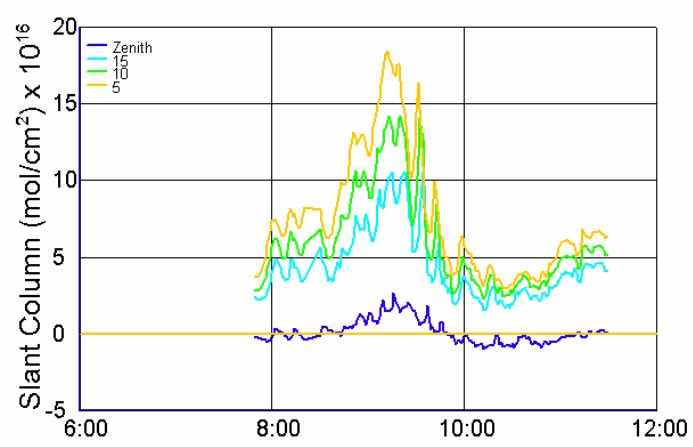

b)

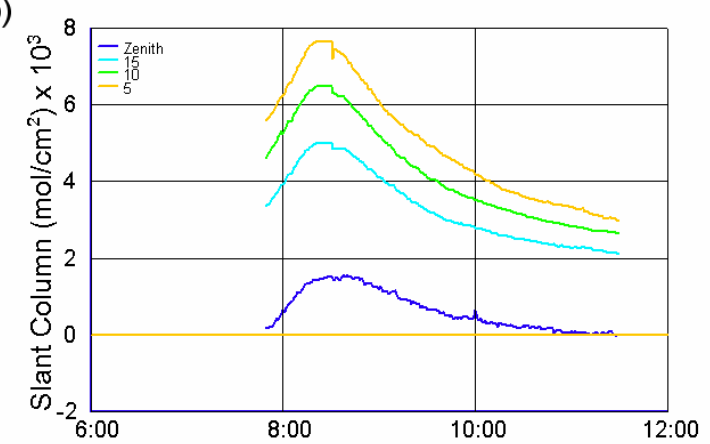


Figure 15

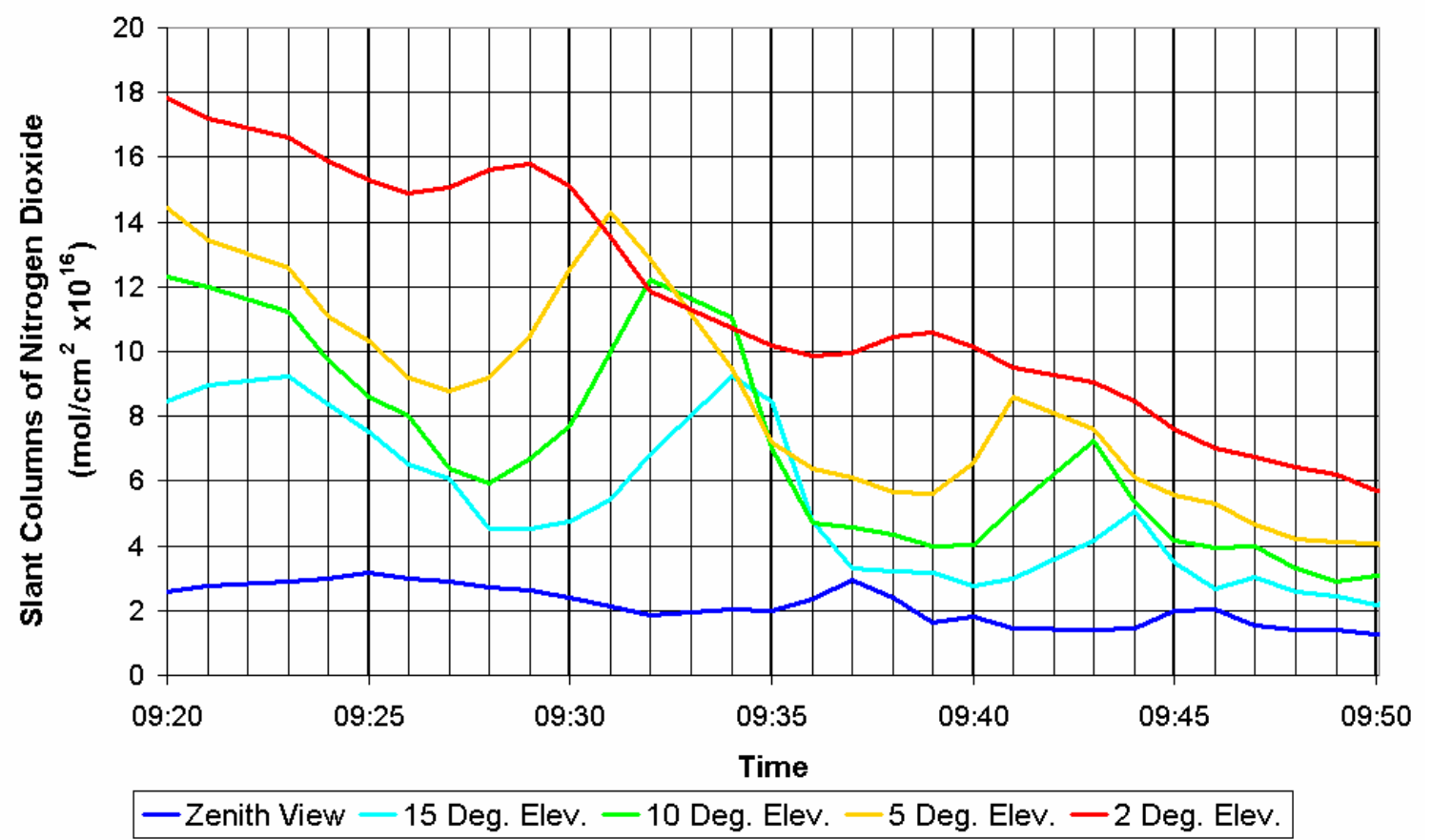


Table1

\begin{tabular}{|c|c|}
\hline Component & Specifications \\
\hline Telescope diameter & $5 \mathrm{~cm}$ \\
\hline Telescope focal length & $10 \mathrm{~cm}$ \\
\hline Fibre-optic length & $10 \mathrm{~m}$ \\
\hline Fibre-optic f-number & 2 \\
\hline Fibre-optic diameter & $200 \mu \mathrm{m}$ \\
\hline Spectrometer & Oriel MS257 \\
\hline Spectrometer focal length & $25 \mathrm{~cm}$ \\
\hline Spectrometer mirrors & $2 \times$ Toroidal \\
\hline Spectrometer f-number & 3.9 \\
\hline Spectrometer entrance slit & $150 \mu \mathrm{m}$ \\
\hline CCD description & $\begin{array}{l}\text { Marconi 48-20, Back-illuminated, Frame Transfer, } \\
\text { UV-Coated }\end{array}$ \\
\hline CCD dimensions & 1072 Columns x 1033 Rows \\
\hline CCD imaging area used & 1052 Columns x 550 Rows \\
\hline CCD integration time & Variable, 0.1 seconds to 60 seconds \\
\hline Grating line density & 600 lines $/ \mathrm{mm}$ \\
\hline Grating blaze wavelength & $400 \mathrm{~nm}$ \\
\hline Wavelength range recorded & $428 \mathrm{~nm}$ to $510 \mathrm{~nm}$ \\
\hline Fitting window used & $431 \mathrm{~nm}$ to $508 \mathrm{~nm}$ \\
\hline Spectral sampling & $0.078 \mathrm{~nm}$ per pixel \\
\hline Instrument line shape & Gaussian, variable from $1.05 \mathrm{~nm}$ to $1.2 \mathrm{~nm}$. \\
\hline Wavelength calibration & Kurucz Solar Spectrum \\
\hline Wavelength accuracy & $<0.04 \mathrm{~nm}$ \\
\hline Temperature Stability & $19{ }^{\circ} \mathrm{C}+/-0.2{ }^{\circ} \mathrm{C}$ \\
\hline
\end{tabular}


Table 2

\begin{tabular}{|c|c|c|c|}
\hline Species & Data Source & $\begin{array}{l}\text { Temperature } \\
/ \mathrm{K}\end{array}$ & Convolution \\
\hline Ozone & 29 & 223 & $\begin{array}{l}\text { Wavelength dependent Gaussian with } \mathrm{I}_{0} \\
\text { correction }\left(1 \times 10^{20} \mathrm{~mol} \mathrm{~cm}^{-2}\right)\end{array}$ \\
\hline $\mathrm{NO}_{2}$ & 30 & 293 & $\begin{array}{l}\text { Wavelength dependent Gaussian with } \mathrm{I}_{0} \\
\text { correction }\left(1 \times 10^{16} \mathrm{~mol} \mathrm{~cm}^{-2}\right)\end{array}$ \\
\hline $\mathrm{H}_{2} \mathrm{O}$ & HITRAN $^{31}$ & - & Standard wavelength dependent Gaussian \\
\hline $\mathrm{O}_{4}$ & $\begin{array}{l}{ }^{27} \text { (corrected for shift } \\
\text { and stretch) }\end{array}$ & - & Standard wavelength dependent Gaussian \\
\hline Ring & $\begin{array}{l}\text { WinDOAS } \\
\text { (calculated, see text) }\end{array}$ & - & Standard wavelength dependent Gaussian \\
\hline
\end{tabular}


Table 3

\begin{tabular}{|l|c|}
\hline Source & Error Estimate \\
\hline Wavelength Calibration & $0.8 \%$ \\
\hline Electronic Noise & $0.2 \%$ \\
\hline Stray Light & Neg. \\
\hline $\begin{array}{l}\text { Asymmetry of Instrument } \\
\text { Line Shape }\end{array}$ & $\begin{array}{c}0.5 \% \\
\text { (see results section) }\end{array}$ \\
\hline $\begin{array}{l}\text { Total single fibre fitting } \\
\text { error }\end{array}$ & $1.5 \%$ \\
\hline $\begin{array}{l}\text { Variability of instrument } \\
\text { line shape }\end{array}$ & $3.5 \%$ (total 5\%) \\
\hline $\begin{array}{l}\text { Additional error due to low } \\
\text { signal on } 2{ }^{\circ} \text { view }\end{array}$ & $5.3 \%$ (total 10.3\%) \\
\hline
\end{tabular}


Table 4

\begin{tabular}{|c|c|c|c|c|c|c||}
\hline & \multicolumn{3}{|c|}{ Peak 1 } & \multicolumn{4}{c|}{$\begin{array}{c}\text { Peak 2 } \\
\text { (passing overhead at 9.36 am) }\end{array}$} & \multicolumn{3}{c||}{ (Passing ovead at 9.46 am) } \\
\hline & $\begin{array}{c}\text { Amplitude } \\
\left(\mathrm{mol} \mathrm{cm}^{-2}\right)\end{array}$ & $\begin{array}{c}\text { Width } \\
(\text { minutes })\end{array}$ & $\begin{array}{c}\text { Peak } \\
\text { Time }\end{array}$ & $\begin{array}{c}\text { Amplitude } \\
\left(\mathrm{mol} \mathrm{cm}^{-2}\right)\end{array}$ & $\begin{array}{c}\text { Width } \\
(\text { minutes })\end{array}$ & Peak Time \\
\hline $2^{\circ}$ & 2.2 & 6.5 & 9.29 & 1 & 4 & $9: 38: 30$ \\
\hline $5^{\circ}$ & 6.5 & 9.5 & $9: 31$ & 3 & 6.5 & $9: 40: 30$ \\
\hline $10^{\circ}$ & 7 & 8.5 & $9: 32: 30$ & 3 & 5.5 & $9: 42: 30$ \\
\hline $15^{\circ}$ & 5.5 & 9 & $9: 34: 30$ & 2.5 & 5.5 & $9: 44$ \\
\hline Zenith & 1 & 4 & $9: 37$ & 0.5 & 3.5 & $9: 45: 30$ \\
\hline
\end{tabular}


Figure Captions.

1. Simplified schematic illustrating paths through the atmosphere of scattered solar radiation detected by the multi-axis DOAS instrument.

2. Schematic representation of the instrumentation used for concurrent Multi-Axis DOAS measurements.

3. Example CCD image with five fibres imaged over a total of 550 rows. Software algorithms adjust for any tilt in the imaged spectra. Charge build-up between reads can be seen at the top of the image.

4. An example DOAS fit of a spectrum taken at $15: 00$ on $9^{\text {th }}$ November $2004\left(80.9^{\circ}\right.$ SZA) using a reference spectrum at solar noon (69.6 $\mathrm{SZA})$ showing fits for $\mathrm{NO}_{2}$ (a), $\mathrm{O}_{3}(\mathrm{~b}), \mathrm{O}_{4}(\mathrm{c}), \mathrm{H}_{2} \mathrm{O}$ (d), Ring (e) with the residual structure (f). Panels (a) to (e) show the fitted cross section in blue with the residual structure in red. Derived slant column densities from this retrieval are $\mathrm{NO}_{2}: 2.05 \times 10^{17} \mathrm{~mol} \mathrm{~cm}^{-2}, \mathrm{O}_{3}$ : $2.37 \times 10^{19} \mathrm{~mol} \mathrm{~cm}^{-2}, \mathrm{H}_{2} \mathrm{O}: 1.26 \times 10^{-3} \mathrm{~mol} \mathrm{~cm}^{-2}, \mathrm{O}_{4}: 4.4 \times 10^{3}$. The residual RMS value is $2.05 \times 10^{-3}$.

5. Spectra from a Quartz-Tungsten radiometric calibration lamp recorded from all five fibres on their respective portions of the 48-20 CCD.

6. Radiometric calibration factors for each pixel of each fibre.

7. Signal intensities measured on each of the five fibres, plotted with the signal intensity measured at off-fibre points. These off-fibres points were measured between the fibres, above the top fibre, and below the bottom fibre, and all have such similar values to be indistinguishable in this Figure.

8. The measured instrument line shape plotted with a fitted Gaussian curve, demonstrating the slight asymmetry of the line shape.

9. The instrument line shape calculated by the WinDOAS software from spectra measured on each section of the CCD. Values plotted are the FWHM of fitted Gaussian curves along the spectrum.

10. Top Panel: Slant column densities of $\mathrm{NO}_{2}$ measured using the four different methods of analysis; Prim/Prim, Sec/Sec, Prim/Sec, and Sec/Prim. Lower Panel: A correlation plot of these four datasets using the Prim/Prim analysis for the $\mathrm{x}$ 
axis. Also included in the lower plot are linear best-fit lines for each dataset, with their equations, showing intercept, gradient, and $\mathrm{R}^{2}$ values.

11. Example fits from spectra from the primary telescope at $3 \mathrm{pm}$ on $9^{\text {th }}$ November 2004 using a reference spectrum from the primary telescope (left), and the secondary telescope (right). Species and concentrations for each panel as are follows: (a) $\mathrm{NO}_{2}, 2.05 \times 10^{17} \mathrm{~mol} \mathrm{~cm}^{-2}$, (b) $\mathrm{O}_{3}, 2.37 \times 10^{19} \mathrm{~mol} \mathrm{~cm}^{-2}$, (c) $\mathrm{O}_{4}, 4.4 \times 10^{3}$. (d) $\mathrm{H}_{2} \mathrm{O}, 1.26 \times 10^{3} \mathrm{~mol} \mathrm{~cm}^{-2}$ (e) Ring, (f) RMS, $2.05 \times 10^{-3}$ (g) $\mathrm{NO}_{2}, 2.06 \times 10^{17} \mathrm{~mol}$ $\mathrm{cm}^{-2}$ (h) $\mathrm{O}_{3}, 1.5 \times 10^{19}$ (i) $\mathrm{O}_{4}, 4.56 \times 10^{3}$, (j) $\mathrm{H}_{2} \mathrm{O}, 1.48 \times 10^{3} \mathrm{~mol} \mathrm{~cm}^{-2}$ (k) RMS $5.28 \times 10^{-3}$.

12. Top panel: Slant column densities from $9^{\text {th }}$ November 2004 using an original zenith reference spectrum, and a spectrum convolved with a broader instrument line shape. Lower panel: A correlation plot of slant column densities retrieved with convolved reference spectra against retrieved concentrations using the original spectrum.

13. Slant column densities for all retrieved absorbers from Thursday $20^{\text {th }}$ May 2004 for all axes. Panels are as follows: (a) $\mathrm{NO}_{2}$, (b) $\mathrm{O}_{3}$, (c) $\mathrm{O}_{4}$, (d) $\mathrm{H}_{2} \mathrm{O}$.

14. Slant column densities of $\mathrm{NO}_{2}$ (panel a) and $\mathrm{O}_{4}$ (panel b) for $17^{\text {th }}$ January 2004 for all axes. The smooth $\mathrm{O}_{4}$ curves indicate a cloud-free period.

15. Slant column density measurements of two plumes from five viewing directions. Transport of the plumes through the viewing geometry can be clearly seen, with peak shape and position giving information on the dynamical progression and geometry of the $\mathrm{NO}_{2}$-rich air mass 


\section{Table Captions}

1. Instrument characteristics for the CMAX-DOAS instrument.

2. Absorption cross sections used in the CMAX-DOAS analysis routine.

3. Theoretical fitting errors for the CMAX-DOAS instrument, based on an investigation of instrumental characteristics (see text).

4. Dimensions of the two plumes identified on the morning of $17^{\text {th }}$ January 2004. Such measurements contain information on plume diameter, concentration and evolution (See also Figure 15). 


\section{References}

1. Noxon, J.F., "Nitrogen Dioxide in the Stratosphere and Troposphere measured by Ground-based absorption spectroscopy." Science, 1975. 189: p. 547-549.

2. Noxon, J.F., E.C. Whipple, and R.S. Hyde, "Stratospheric NO2, 1. Observational method and behaviou at Midlatitudes." Journal of Geophysical ResearchAtmospheres, 1979. 84: p. 5047-5076.

3. Solomon, S., A.L. Schmeltekopf, and R.W. Sanders, "On the interpretation of zenith sky measurements". Journal of Geophysical Research-Atmospheres, 1987. 92(D7): p. 8311-8319.

4. Johnston, P.V. and R.L. McKenzie, "NO2 Observations at 45-Degrees-S During the Decreasing Phase of Solar-Cycle 21, from 1980 to 1987". Journal of Geophysical Research-Atmospheres, 1989. 94(D3): p. 3473-3486.

5. Van Roozendael, M., C. Hermans, M. Demaziere, and P.C. Simon, "Stratospheric NO2 observations at the Jungfraujoch Station between June 1990 and May 1992". Geophysical Research Letters, 1994. 21: p. 1383-1386.

6. Aliwell, S.R., M. Van Roozendael, P.V. Johnston, A. Richter, T. Wagner, D.W. Arlander, J.P. Burrows, D.J. Fish, R.L. Jones, K.K. Tornkvist, J.C. Lambert, K. Pfeilsticker, and I. Pundt, "Analysis for BrO in zenith-sky spectra: An intercomparison exercise for analysis improvement". Journal of Geophysical Research-Atmospheres, 2002. 107(D14): p. art. no.-4199.

7. Richter, A., M. Eisinger, A. Ladstatter-Weissenmayer, and J.P. Burrows, "DOAS Zenith sky observations: 2. Seasonal variation of BrO over Bremen (53 degrees N) 1994-1995". Journal of Atmospheric Chemistry, 1999. 32(1): p. 83-99.

8. Friess, U., T. Wagner, I. Pundt, K. Pfeilsticker, and U. Platt, "Spectroscopic measurements of tropospheric iodine oxide at Neumayer Station, Antarctica". Geophysical Research Letters, 2001. 28(10): p. 1941-1944.

9. Wittrock, F., R. Muller, A. Richter, H. Bovensmann, and J.P. Burrows, "Measurements of iodine monoxide (IO) above Spitsbergen". Geophysical Research Letters, 2000. 27(10): p. 1471-1474.

10. Tornkvist, K.K., D.W. Arlander, and B.-M. Sinnhuber, "Ground-based UV measurements of BrO and OClO over Ny-Alesund during winter 1996 and 1997 and Andoya during winter 1998/99". Journal of Atmospheric Chemistry, 2002. 43: p. 75-106.

11. Solomon, S., A.L. Schmeltekopf, and R.W. Sanders, "On the Interpretation of Zenith Sky Absorption-Measurements". Journal of Geophysical ResearchAtmospheres, 1987. 92(D7): p. 8311-8319.

12. Sanders, R.W., S. Solomon, J.P. Smith, L. Perliski, H.L. Miller, G.H. Mount, J.G. Keys, and A.L. Schmeltekopf, "Visible and near-Ultraviolet Spectroscopy at Mcmurdo Station, Antarctica 9. Observations of OClO from April to October 1991". Journal of Geophysical Research-Atmospheres, 1993. 98(D4): p. 72197228.

13. Miller, H.L., A. Weaver, R.W. Sanders, K. Arpag, and S. Solomon, "Measurements of arctic sunrise surface ozone depletion events at Kangerlussuaq, Greenland (67 degrees N, to 51 degrees W)". Tellus Series B-Chemical and Physical Meteorology, 1997. 49(5): p. 496-509. 
14. Honninger, G. and U. Platt, "Observations of BrO and its vertical distribution during surface ozone depletion at Alert". Atmospheric Environment, 2002. 36(1516): p. 2481-2489.

15. Bobrowski, N., G. Honninger, B. Galle, and U. Platt, "Detection of bromine monoxide in a volcanic plume". Nature, 2003. 423(6937): p. 273-276.

16. Leser, H., G. Honninger, and U. Platt, "MAX-DOAS measurements of BrO and NO2 in the marine boundary layer". Geophysical Research Letters, 2003. 30(10): p. art. no. -1537.

17. Honninger, G., H. Leser, O. Sebastian, and U. Platt, "Ground-based measurements of halogen oxides at the Hudson Bay by active longpath DOAS and passive MAX-DOAS". Geophysical Research Letters, 2004. 31(4): p. art. no.L04111.

18. Wittrock, F., H. Oetjen, A. Richter, S. Fietkau, T. Medeke, A. Rozanov, and J.P. Burrows, "MAX-DOAS measurements of atmospheric trace gases in Ny-Alesund - Radiative transfer studies and their application". Atmospheric Chemistry and Physics, 2004. 4: p. 955-966.

19. Platt, U., Differential optical absorption spectroscopy, (DOAS), in air monitoring by spectroscopic techniques., in Chemical Analysis, M.W. Sigrist, Editor. 1994, Wiley: New York.

20. DEFRA, Nitrogen Dioxide in the United Kingdom. 2003: Department for Environment, Food and Rural Affairs, The Scottish Executive, The National Assembly for Wales and The Department of the Environment in Northerm Ireland. The Air Quality Expert Group.

21. Oriel, The Book of Photon Tools, in http://www.oriel.com. 2001, Oriel corporation.

22. Grainger, J.F. and J. Ring, "Anomalous Fraunhofer line profiles". Nature, 1962. 193(762).

23. Fayt, C. and M. Van Roozendael," WINDOAS user manual", http://www.oma.be/BIRA-IASB/Molecules/BrO/WinDOAS-SUM-210b.pdf., Editor. 2001.

24. Kurucz, R.L., I. Furenlid, J. Brault, and L. Testerman, Solar Flux Atlas from 296 to 1300nm, in National Solar Observatory Atlas No. 1. 1984.

25. Honninger, G., C. von Friedeburg, and U. Platt, "Multi axis differential optical absorption spectroscopy (MAX-DOAS)". Atmospheric Chemistry and Physics, 2004. 4: p. 231-254.

26. Stutz, J.," Charakterisierung von Photodiondenzeilen zue Messung stratospharischer Spurenstoffe". 1991, University of Heidelberg.

27. Greenblatt, G.D., J.J. Orlando, J.B. Burkholder, and A.R. Ravishankara, "Absorption-Measurements of Oxygen between 330nm and 1140nm". Journal of Geophysical Research-Atmospheres, 1990. 95(D11): p. 18577-18582.

28. Wagner, T., B. Dix, C. von Friedeburg, U. Friess, S. Sanghavi, R. Sinreich, and U. Platt, "MAX-DOAS O-4 measurements: A new technique to derive information on atmospheric aerosols - Principles and information content". Journal of Geophysical Research-Atmospheres, 2004. 109(D22): p. art. no.D22205. 
29. Bogumil, K., J. Orphal, T. Homann, S. Voigt, P. Spietz, O.C. Fleischmann, A. Vogel, M. Hartmann, H. Kromminga, H. Bovensmann, J. Frerick, and J.P. Burrows, "Measurements of molecular absorption spectra with the SCIAMACHY pre-flight model: instrument characterization and reference data for atmospheric remote-sensing in the 230-2380 nm region". Journal of Photochemistry and Photobiology a-Chemistry, 2003. 157(2-3): p. 167-184.

30. Vandaele, A.C., C. Hermans, P.C. Simon, M. Carleer, R. Colin, S. Fally, M.F. Merienne, A. Jenouvrier, and B. Coquart, "Measurements of the NO2 absorption cross-section from $42000 \mathrm{~cm}(-1)$ to $10000 \mathrm{~cm}(-1)(238-1000 \mathrm{~nm})$ at $220 \mathrm{~K}$ and 294 K". Journal of Quantitative Spectroscopy \& Radiative Transfer, 1998. 59(35): p. 171-184.

31. Rothman, L.S., A. Barbe, D.C. Benner, L.R. Brown, C. Camy-Peyret, M.R. Carleer, K. Chance, C. Clerbaux, V. Dana, V.M. Devi, A. Fayt, J.M. Flaud, R.R. Gamache, A. Goldman, D. Jacquemart, K.W. Jucks, W.J. Lafferty, J.Y. Mandin, S.T. Massie, V. Nemtchinov, D.A. Newnham, A. Perrin, C.P. Rinsland, J. Schroeder, K.M. Smith, M.A.H. Smith, K. Tang, R.A. Toth, J. Vander Auwera, P. Varanasi, and K. Yoshino, "The HITRAN molecular spectroscopic database: edition of 2000 including updates through 2001". Journal of Quantitative Spectroscopy \& Radiative Transfer, 2003. 82(1-4): p. 5-44. 